\title{
Hydrodynamics and mass transfer in segmented flow small channel contactors for uranium extraction
}

Eduardo Garciadiego-Ortega, Dimitrios Tsaoulidis, Miguel Pineda, Eric S. Fraga, and Panagiota Angeli*

ThAMeS Multiphase, Department of Chemical Engineering, University College London, WC1E 7JE, London, UK

*corresponding author: p.angeli@ucl.ac.uk

\section{Abstract}

In this work, the extraction of $\mathrm{U}(\mathrm{VI})$ by tributyl phosphate (TBP) is studied in small channels of different sizes, operated in segmented flow. The variables analysed include the channel diameter (1 to $4 \mathrm{~mm}$ I.D.), mixture velocity $\left(1.06\right.$ to $\left.4.24 \mathrm{~cm} \mathrm{~s}^{-1}\right)$, volume fraction of the continuous phase (between 0.200 and 0.500 ), and concentration of extractant (TBP $30 \% \mathrm{v} / \mathrm{v}$ in kerosene and TBP 100\%). The hydrodynamic characteristics of the flow, such as plug and slug lengths, specific interfacial area, and dispersed phase holdup, were obtained experimentally using high-speed imaging, while the pressure drop was measured with a differential pressure transducer. These parameters were correlated to the studied variables. The concentration of uranium in the aqueous phase was measured with UV-Vis spectroscopy, and the mass transfer coefficients were compared with the predictions of a numerical model of segmented flow developed in Comsol Multiphysics, with good agreement.

\section{Keywords}

Segmented flow, Liquid-liquid extraction, interfacial mass transfer, pressure drop, high-speed imaging 


\section{Introduction}

Reprocessing of spent nuclear fuel reduces the volume and toxicity of radioactive waste and can improve the sustainability of nuclear power generation. A common section of reprocessing is the PUREX process (Plutonium Uranium Redox EXtraction), which is based on liquid-liquid extractions and is used to recover the fissionable and fertile isotopes of $U$ and Pu for further energy production [1,2]. The contactors commonly used in the PUREX process are batteries of mixer-settlers or pulsed columns. These contactors require large solvent inventories, have limitations in the viscosity (up to $2 \mathrm{mPa}$ for the organic phase [3]) and the density difference (at least $100 \mathrm{~kg} \mathrm{~m}^{-3}$ [3]) they can handle, wide residence time distributions, and complex flow fields that are not easily characterised.

Recent developments have shown that multiphase flows in small channels can intensify processes such as liquid-liquid extractions [4-6]. From the various patterns which can form in small channels, the plug or segmented one appears under a wide range of conditions and has been associated with increased mass transfer rates. It consists of regular elongated drops (plugs) separated by the continuous phase (slugs), whilst a thin film separates the plugs from the wall (Fig. 1). Circulation patterns form within the plugs and slugs which enhance mixing $[7,8]$. The short diffusion distances, large interfacial area, and intense mixing within each phase enhance the mass transfer rates. Furthermore, the regularity and symmetry of this flow pattern helps its numerical modelling. To model a mass transfer process under segmented flow, the geometry of the plug-slug unit has to be well known.

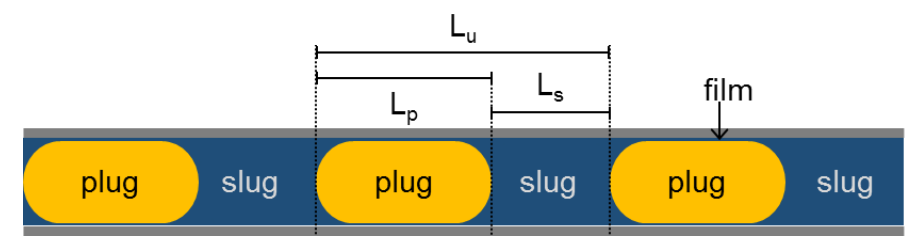

Fig. 1. Schematic of the liquid-liquid segmented flow pattern. $L_{u}, L_{p}$, and $L_{s}$ are the unit, plug, and slug lengths, respectively. 
There is a large number of studies on different aspects of segmented flow, including plug length, interfacial area, pressure drop, and mass transfer coefficients. A number of parameters have been considered, such as flow rates, liquids used, the geometry of the inlet section, and the size of the channel. Researchers usually study only some aspects of the flow, which makes it difficult to reach generalised conclusions on the effects of the various parameters. However, some common conclusions can be drawn. Plugs are shorter as the velocities increase and strongly depend on the inlet flow rate ratio [8-12]. Shorter plugs have a larger interfacial area per unit volume [13-16]. The pressure gradient is usually modelled with the Hagen-Poiseuille equation where a term that accounts for the plug is included $[8,17-$ 20]. The volumetric mass transfer coefficient $\left(K_{\llcorner} a\right)$ is larger than in conventional contactors. KLa decreases with increasing channel size and increases with velocity [13,21-24]. According to Sattari-Najafabadi et al., there is not sufficient understanding of the effects of the physical properties of the fluids and the channel geometry on the pressure drop and mass transfer [25]. To design optimal segmented flow contactors and compare them with conventional equipment, it is crucial to quantitatively relate the design and operational variables to the hydrodynamics and mass transfer characteristics.

The extraction of radionuclides in intensified contactors has attracted considerable attention in the last decade. Mariet et al. [26] reviewed the extraction of uranium in small channels and suggested that the large interfacial area and the fast mixing in segmented flows offer advantages for radiochemical applications. Sen et al. [27] and Darekar et al. [28-30] studied $\mathrm{U}(\mathrm{VI})$ extraction from a nitric acid solution to a tributyl phosphate (TBP) in kerosene solution in microchannels $(\mathrm{d} \leq 2 \mathrm{~mm})$ with $\mathrm{T}$ - and $\mathrm{Y}$-junction inlets. These authors found important advantages over conventional contactors, including large extraction efficiencies (at short processing times, below $60 \mathrm{~s}$ ), low pressure drop, simple phase separation (short coalescence times). Tsaoulidis et al. and Li \& Angeli showed that, in contrast to pulsed columns and mixer-settlers, high viscosity organic phases can be used in extractions in small channels $[12,13,20,24]$. These authors used high viscosity ionic liquids and achieved high 
extraction efficiencies of $U$ and $E u$ in short timescales, which is particularly important for solvent radiolysis. Wang et al. recently suggested that segmented flow contactors are suitable for small scale treatment of hazardous radionuclides but effective scale-up, by increasing the number of small units, is necessary [31]. Bascone et al. simulated the co-decontamination part of a PUREX flowsheet and showed that by using small channel contactors instead of pulsed columns and mixer-settlers, there are improvements in terms of inherent safety (including reduced equipment size and solvent inventories), solvent degradation, volume of hazardous materials involved, and costs, compared to conventional contactors [32,33].

In this paper, the hydrodynamics and mass transfer during the extraction of uranyl nitrate in tributyl phosphate (TBP) solutions, relevant to spent nuclear fuel reprocessing, are investigated. Small circular channels are used, with diameters ranging between 1 and $4 \mathrm{~mm}$. For the conditions investigated, segmented flow establishes in the channels. The effects of design and operational parameters such as TBP concentration, phase flow rate ratio, channel diameter and mixture velocity on the hydrodynamic characteristics and the extraction performance are investigated. Correlations based on dimensionless numbers are proposed for the main hydrodynamic parameters, including plug/slug/unit lengths, holdup, interfacial area and pressure gradient. The extraction efficiency and mass transfer coefficients are further compared against those from conventional contactors. A simplified numerical model was able to predict the mass transfer in segmented flow reasonably well. The findings show that segmented flow contactors have high mass transfer rates, while, importantly, they can accommodate fluids with high viscosities; in the case of uranyl nitrate extraction, pure TBP can be used as extractant instead of the conventional TBP solution in an organic phase, which improves significantly the mass transfer.

\section{Materials and methods}

For the hydrodynamic studies, reported in sections 3.1 and 3.2, the aqueous phase was deionised water while the organic phase was either pure TBP (obtained from Sigma- 
Aldrich, UK) or a mixture of $30 \% \mathrm{v} / \mathrm{v}$ TBP in kerosene (obtained from Alfa Aesar, UK). Both phases were saturated with each other by first mixing them and then leaving them overnight. The properties of the phases can be seen in Table 1. The densities were measured gravimetrically, the viscosities were measured with a cone-plate rheometer (MCR302 Anton Paar, AUT), and the interfacial tensions were measured with a Du Nouy tensiometer (K100 Krüss, GER). For the mass transfer studies reported in section 3.3, the aqueous phase is substituted with a 3 mol L ${ }^{-1}$ nitric acid $\left(\mathrm{HNO}_{3}\right.$, Sigma-Aldrich, UK) solution. Uranyl nitrate hexahydrate $\left(\mathrm{UO}_{2}\left(\mathrm{NO}_{3}\right)_{2} \cdot 6 \mathrm{H}_{2} \mathrm{O}, \mathrm{U}(\mathrm{VI})\right)$ was dissolved in the aqueous phase after the acid phase was saturated with the respective organic phase. The properties of the $\mathrm{HNO}_{3}$ solution are very similar to water (e.g. density of $1070 \mathrm{~kg} \mathrm{~m}^{-3}$ and viscosity of $1 \mathrm{mPa}$ [ [24]).

Table 1. Properties of the liquid phases used at room temperature $\left(20^{\circ} \mathrm{C}\right)$. Both phases are mutually saturated.

\begin{tabular}{|c|c|c|c|}
\hline Liquid phase & $\begin{array}{c}\text { Density }(\rho) / \\
\mathrm{kg} \mathrm{m}^{-3}\end{array}$ & $\begin{array}{c}\text { Viscosity }(\mu) / \\
\mathrm{mPa} \mathrm{s}\end{array}$ & $\begin{array}{c}\text { Interfacial tension }(\mathrm{\gamma}) / \\
\mathrm{mN} \mathrm{m}^{-1}\end{array}$ \\
\hline Water sat. with TBP & 993.3 & 0.9405 & - \\
\hline Water sat. with TBP 30\% & 993.0 & 0.9620 & 7.714 \\
\hline TBP sat. with water & 973.3 & 4.355 & 9.950 \\
\hline $\begin{array}{c}\text { TBP 30\% v/v in kerosene } \\
\text { sat. with water }\end{array}$ & 844.3 & 2.256 & \\
\hline
\end{tabular}

The studies were carried out in the experimental set up shown in Fig. 2. It consists of two syringe pumps (Legato210 kdScientific, USA), one for each phase, the test section and a flow separator (SEP-10 Zaiput, USA) at the end of the section. Test sections with internal diameters (d) 1 (Idex, USA), 2 (Idex, USA), and 4 (BOLA, GER) mm were used, made of fluoropolymer tubing (PFA). The two phases join at a T-junction made of PTFE with side channels of the same diameter as the main test section ( 1 and $2 \mathrm{~mm}$ tees were made in-house by drilling through commercially available ones, supplied by Idex, USA; $4 \mathrm{~mm}$ tees were from 
BOLA, GER). In the T-junction, the organic (continuous) phase was fed at the inlet which is at the same axis as the main channel, while the aqueous (dispersed) phase was fed perpendicularly to the main channel. The flow patterns were recorded with a high-speed camera (v1212 Phantom, USA). For the imaging, visualisation boxes were used around the test tube, made of transparent polystyrene and filled with a glycerol-in-water $10 \% \mathrm{w} / \mathrm{w}$ mixture to match the refractive index of the fluoropolymer tubing. The high-speed images were analysed to measure the plug and slug lengths of the segmented flow pattern. The resolution of the images depends on the channel internal diameter since the camera focus was adjusted for each channel diameter. They are $101 \mathrm{px} \mathrm{mm}^{-1}, 51.5 \mathrm{px} \mathrm{mm}^{-1}$, and $12.8 \mathrm{px} \mathrm{mm}^{-1}$ for the 1 , 2, and $4 \mathrm{~mm}$ ID channels, respectively. The error bars in Figs. 3, to 6 correspond to standard deviations from 5 measurements.

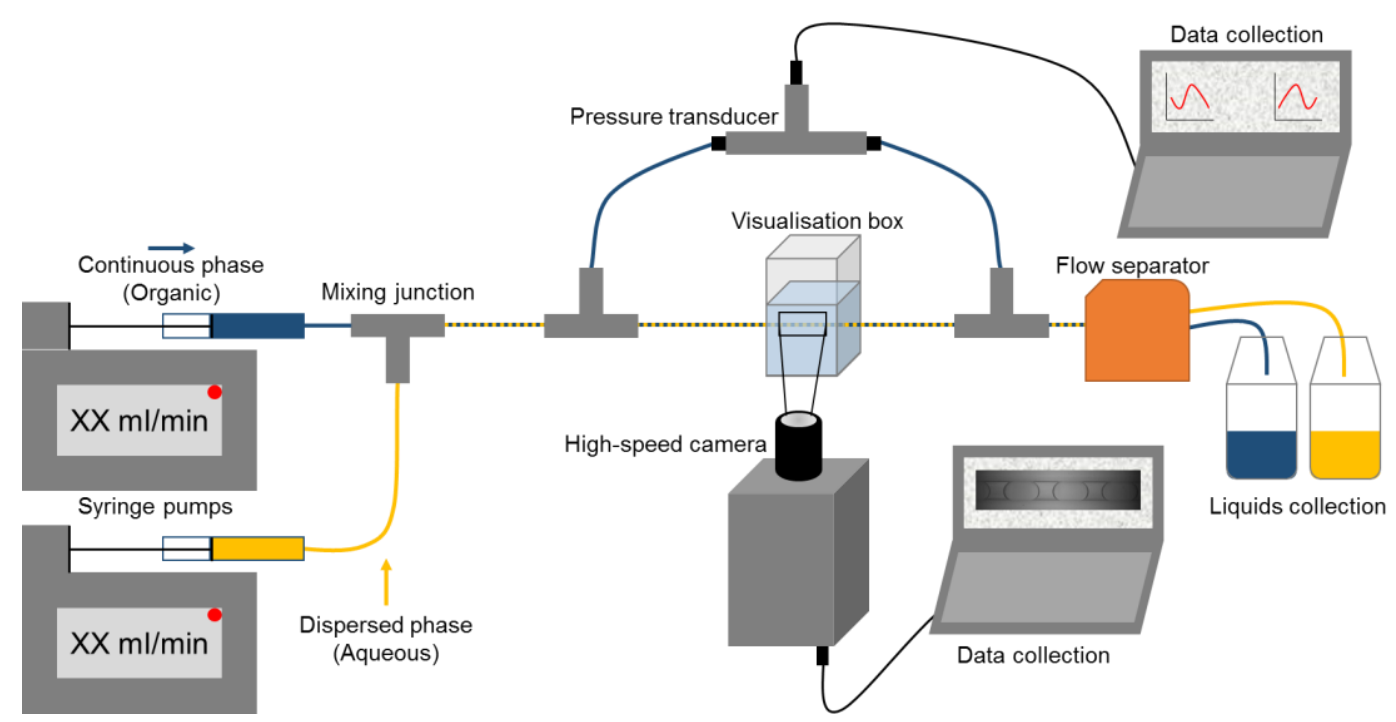

Fig. 2. Schematic of flow setup for high-speed imaging, pressure drop, and mass transfer studies.

Pressure drop was measured with a differential pressure transducer (UNIK 5000 GE, USA). The pressure ports have the same internal diameter as the test section and no disruption to the flow was seen. The tubing to the pressure transducer was filled with the continuous phase in the main channel. The distances between the ports were 62.6, 78.2, $133.0 \mathrm{~cm}$ for the 1, 2, $4 \mathrm{~mm}$ ID test sections, respectively. The first port is placed at least $40 \times \mathrm{d}$ units away from the T-junction to ensure that the flow pattern is fully developed. Measurements 
were taken over $20 \mathrm{~s}$ with a $5 \mathrm{kHz}$ frequency, using Labview. The error bars in Figs. 7 and 8 correspond to the standard deviation of $\sim 20,000$ data points.

In the mass transfer experiments, the concentration of $\mathrm{U}(\mathrm{VI})$ in the aqueous phase was measured at the outlet using a UV-vis spectrometer (USB2000+ Ocean Optics, USA). The average absorption between 415 and $420 \mathrm{~nm}$ wavelengths was used in all measurements. Solutions of known concentration were prepared to calibrate the equipment. Distribution coefficients were measured in batch equilibrium experiments for both TBP 100\% and TBP $30 \%$ solutions at 1:1 volume ratios and mixed over 3 hours. The distribution coefficients (D) of $\mathrm{U}(\mathrm{VI})$ concentration in the organic over the aqueous phases were $28.7 \pm 1.8$ for TBP $100 \%$ and $8.10 \pm 0.36$ for TBP $30 \%$, respectively, where the standard deviations correspond to three repetitions. As can be seen, the use of pure TBP can intensify the process; at equilibrium, only $3.4 \%$ of the initial $\mathrm{U}(\mathrm{VI})$ remains in the aqueous phase when TBP $100 \%$ is used, compared to $11 \%$ for TBP $30 \%$.

Experiments were carried out in all three test sections (1, 2, $4 \mathrm{~mm}$ ID) with both the $100 \%$ TBP and the $30 \%$ TBP/kerosene as the organic phase. For the hydrodynamic studies (Sections 3.1, 3.2), four mixture velocities $\left(u_{\text {mix }}\right)\left(1.06,2.12,3.18,4.24 \mathrm{~cm} \mathrm{~s}^{-1}\right)$ and four organic phase flow rate fractions $(0.500,0.333,0.250,0.200)$ were used in the three channel sizes. The mixture velocity is calculated as the total flowrate $\left(Q_{T}\right)$, which is equal to the sum of the volumetric flow rates of the two phases, divided by the channel cross-sectional area. The organic phase flow rate fraction is found by dividing the organic phase flow rate $\left(Q_{c}\right)$ by the total flowrate. The mass transfer experiments were carried out at two mixture velocities (1.06, $\left.4.24 \mathrm{~cm} \mathrm{~s}^{-1}\right)$ and three organic phase flow rate fractions $(0.500,0.333,0.250)$. The initial concentration of $\mathrm{UO}_{2}\left(\mathrm{NO}_{3}\right)_{2} \cdot 6 \mathrm{H}_{2} \mathrm{O}$ was $0.05 \mathrm{~mol} \mathrm{~L}^{-1}$ in the nitric acid solution for all cases studied. The following conditions were selected as base case: TBP $30 \%, d=2 \mathrm{~mm}, u_{\text {mix }}=1.06$ $\mathrm{cm} \mathrm{s}^{-1}, 0.500$ organic phase flow rate fraction. Three residence times were considered, equal to 5,10 , and $20 \mathrm{~s}$, which were obtained by changing the channel length.

The numerical model used to study the mass transfer of $\mathrm{U}(\mathrm{VI})$ from the aqueous to the organic phase was discussed in Tsaoulidis \& Angeli [24]. In the model it is assumed that the 
effect of gravity is negligible, the liquids are Newtonian and incompressible, and the properties (viscosities, densities, interfacial tension) are independent of the $\mathrm{U}(\mathrm{VI})$ concentrations. $\mathrm{A}$ single plug-slug unit cell is simulated with the plug in the centre, while periodic boundary conditions are applied at the ends of the unit for the pressure, the velocity, and the concentrations. The shape and position of the plug remain fixed, while the wall of the channel moves with a constant velocity equal to the plug velocity, but with a direction opposite to the flow. Cylindrical coordinates are used along with angular symmetry and only half of the 2-D unit cell is modelled. The plugs are assumed to have a cylindrical body with hemispherical caps; the plug and slug lengths are taken from the experiments. The film thickness and plug velocity are calculated from correlations given by Mac Giolla Eain et al. [34] and Abiev et al. [15], respectively. The solute diffusivities in the model are $10^{-9} \mathrm{~m}^{2} \mathrm{~s}^{-1}[35], 1.03 \times 10^{-10} \mathrm{~m}^{2} \mathrm{~s}^{-1}$ [36], and $2.56 \times 10^{-10} \mathrm{~m}^{2} \mathrm{~s}^{-1}$ [36] for the aqueous, the $100 \%$ TBP and $30 \%$ TBP phases respectively.

The model was solved using COMSOL Multiphysics 5.4 with the 'Laminar Flow' and 'Transport of Diluted Species' physics modules. First, the Navier-Stokes and continuity equations were solved for both liquid domains (or phases) in steady-state to determine the velocity and pressure profiles. Subsequently, the transient convection-diffusion equations, one for each domain, were solved to obtain the mass transfer during the movement of the plug along the channel. The initial conditions are zero concentration of solute within the slug and $0.05 \mathrm{~mol} / \mathrm{L}$ within the plug. The model also assumes zero flux and non-slip boundary conditions at the channel walls. For the whole computational domain, a free triangular mesh was used, which was additionally refined along the interface and the channel wall. In all cases, the minimum and maximum element sizes along the interface were $0.02 \mu \mathrm{m}$ and $0.4 \mu \mathrm{m}$, respectively. The minimum element size along the walls is $0.1 \mu \mathrm{m}$ and inside each phase domain, away from the interphase, is $1.5 \mu \mathrm{m}$. Further refinements to the grid were not found to affect the results. Moreover, the very fine grid size used ensures that numerical diffusion is minimal. For the integration of the convection-diffusion equations, a time step of $0.05 \mathrm{~s}$ was used. Because of the initial condition used, very large instantaneous fluxes would occur across 
the interface, which could lead to initial concentration oscillations and slightly negative values in regions where the concentration is zero initially. To mitigate this problem, the interphase discontinuity is replaced by a step function across the interface, as described by Tsaoulidis \& Angeli [24].

\section{Results and Discussion}

\subsection{Hydrodynamic features of segmented flow}

The experimental results of plug and slug lengths under various conditions are presented here. From the experimental data, the dimensionless plug length $\left(L_{p} / d\right)$ and the slug length fraction $\left(1-L_{p} / L_{u}\right)$ were found to best correlate with the following dimensionless numbers: the continuous (organic) phase flow rate fraction $\left(Q_{d} / Q_{T}\right)$, the dispersed to continuous phase viscosity ratio $\left(\mu_{d} / \mu_{c}\right)$, the capillary number based on the continuous phase $\left(C a_{c}=\mu_{c} \times u_{\text {mix }} / y\right)$, and the ratio of the Reynolds $\left(\operatorname{Re}_{\mathrm{c}}=\rho_{\mathrm{c}} \times \mathrm{umix}_{\mathrm{mix}} \times \mathrm{d} / \mu_{\mathrm{c}}\right)$ and capillary numbers of the continuous phase $\left(\operatorname{Re}_{\mathrm{c}} / \mathrm{Ca}_{\mathrm{c}}=\rho_{\mathrm{c}} \times \gamma \times \mathrm{d} / \mu_{\mathrm{c}}{ }^{2}\right)$. Eqs. 1 and 2 present the correlations and Table 2 lists the coefficients with $95 \%$ confidence intervals, the $\mathrm{R}^{2}$ of the regressions and the range of the input variables. The measured ranges of $L_{p} / d$ and $1-L_{p} / L_{u}$ are $[1.36-5.60]$ and $[0.576-0.879]$, respectively. The ratio $\mathrm{Re}_{c} / \mathrm{Ca}_{c}$ can be omitted in Eq. 2 because it was found that the $p$-value, a measure of how much a variable affects the results compared to random chance, was above $0.05(p$-value $=0.30)[37]$.

$$
\begin{aligned}
& \ln \left(\frac{\mathrm{L}_{\mathrm{p}}}{\mathrm{d}}\right)=\mathrm{a}_{1}+\mathrm{a}_{2} \ln \left(\frac{\mathrm{Q}_{\mathrm{c}}}{\mathrm{Q}_{\mathrm{T}}}\right)+\mathrm{a}_{3} \ln \left(\frac{\mu_{\mathrm{d}}}{\mu_{\mathrm{c}}}\right)+\mathrm{a}_{4} \ln \left(\mathrm{Ca}_{\mathrm{c}}\right)+\mathrm{a}_{5} \ln \left(\frac{\mathrm{Re}_{\mathrm{c}}}{\mathrm{Ca_{ \textrm {c } }}}\right) \\
& \ln \left(1-\frac{\mathrm{L}_{\mathrm{p}}}{\mathrm{L}_{\mathrm{u}}}\right)=\mathrm{b}_{1}+\mathrm{b}_{2} \ln \left(\frac{\mathrm{Q}_{\mathrm{c}}}{\mathrm{Q}_{\mathrm{T}}}\right)+\mathrm{b}_{3} \ln \left(\frac{\mu_{\mathrm{d}}}{\mu_{\mathrm{c}}}\right)+\mathrm{b}_{4} \ln \left(\mathrm{Ca}_{\mathrm{c}}\right)
\end{aligned}
$$

Table 2 Regression results and range of variables for Eqs. 1 and 2. The confidence intervals correspond to $95 \%$. The range of $\mathrm{Re}_{\mathrm{c}}$ is added for reference.

\begin{tabular}{|c|c|c|c|}
\hline Coefficient & a & b & Variable range \\
\hline
\end{tabular}




\begin{tabular}{|l|c|c|c|}
\hline 1 & $-2.56 \pm 0.65$ & $-0.82 \pm 0.39$ & - \\
\hline $2\left(\mathrm{Q}_{\mathrm{c}} / \mathrm{Q}_{\mathrm{T}}\right)$ & $-0.872 \pm 0.063$ & $1.181 \pm 0.038$ & $0.2-0.5$ \\
\hline $3\left(\mu_{\mathrm{d}} / \mu_{\mathrm{c}}\right)$ & $-0.36 \pm 0.15$ & $-0.099 \pm 0.089$ & $0.2160-0.4264$ \\
\hline $4\left(\mathrm{Ca}_{\mathrm{c}}\right)$ & $-0.280 \pm 0.069$ & $-0.130 \pm 0.042$ & $2.406 \times 10^{-3}-2.396 \times 10^{-2}$ \\
\hline $5\left(\mathrm{Re}_{\mathrm{c}} / \mathrm{Ca}_{\mathrm{c}}\right)$ & $0.099 \pm 0.061$ & - & $395.9-6602$ \\
\hline $\mathrm{Re}_{\mathrm{c}}$ & - & - & $2.371-63.53$ \\
\hline $\mathrm{R}^{2}$ & 0.944 & 0.983 & \\
\hline
\end{tabular}

The values of the coefficients in both Eqs. 1 and 2 show that $Q_{d} / Q_{T}$ and $C a_{c}$ have the largest values with the lowest relative confidence intervals. This indicates that $L_{p} / d$ and (1$\mathrm{L}_{\mathrm{p}} / \mathrm{L}_{\mathrm{u}}$ ) are most sensitive to changes in $\mathrm{Q}_{\mathrm{d}} / \mathrm{Q}_{\mathrm{T}}$ and $\mathrm{Ca}_{\mathrm{c}}$, compared to $\mu_{\mathrm{d}} / \mu_{\mathrm{c}}$ or $\mathrm{Re}_{\mathrm{c}} / \mathrm{Ca}_{\mathrm{c}}$. As less dispersed phase is added (higher $Q_{d} / Q_{T}$ ), the plugs become shorter (lower $L_{p} / d$ ). The effect of the capillary number is explained by the forces at the inlet; higher $\mathrm{Ca}_{\mathrm{c}}$ implies higher velocity at the $\mathrm{T}$-junction that tends to break the forming plugs with higher frequency. The viscosity ratio is important for $L_{p} / d$ but not as important for $L_{p} / L_{u}$, while the effect of $R e_{c} / C a_{c}$, for the ranges investigated, is small but not negligible. The goodness-of-fit for both regressions is shown in Figs. 3 and 4. Most experimental results are contained within $20 \%$ of the predicted values. These results were obtained using two fluid pairs, namely, water-TBP $30 \%$ and waterTBP $100 \%$, and the regression coefficients should be applied cautiously to other fluid systems. However, the overall dependencies of the lengths from the input variables will likely hold for geometrically similar systems (T-junctions and circular channels). Despite using five and four adjustable parameters to model $L_{p} / d$ and $\left(1-L_{p} / L_{u}\right)$, respectively, deviations are still observed in Figs. 3 and 4. This can be attributed to experimental error as well as to the simple powerlaw used to correlate the data. 


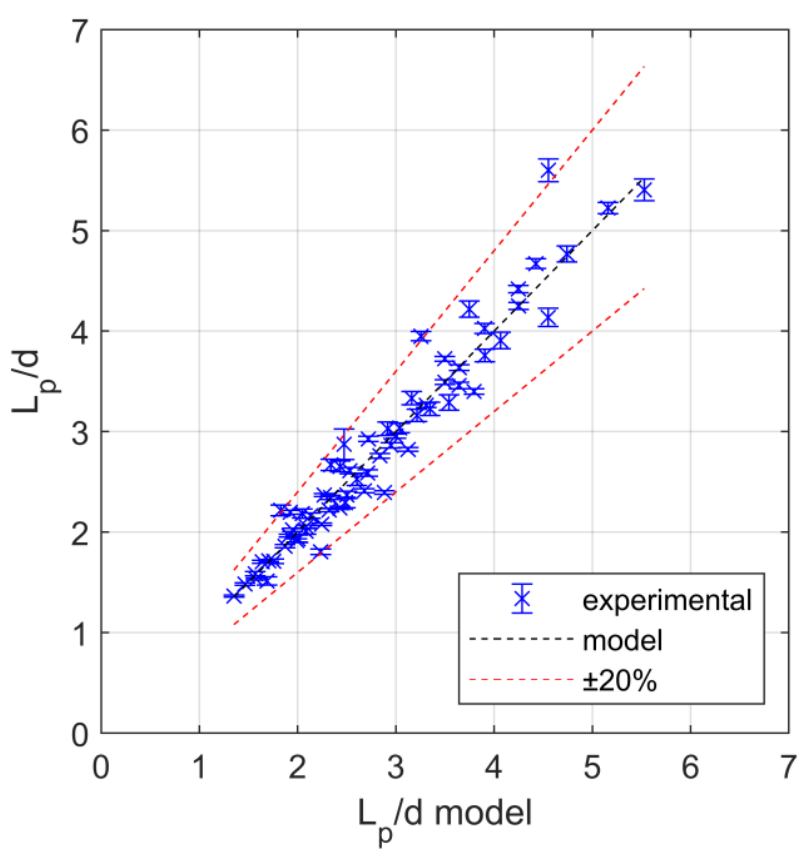

Fig. 3. $L_{p} / d$ predicted from Eq. 1 against experimental results with $20 \%$ bands for all cases studied.

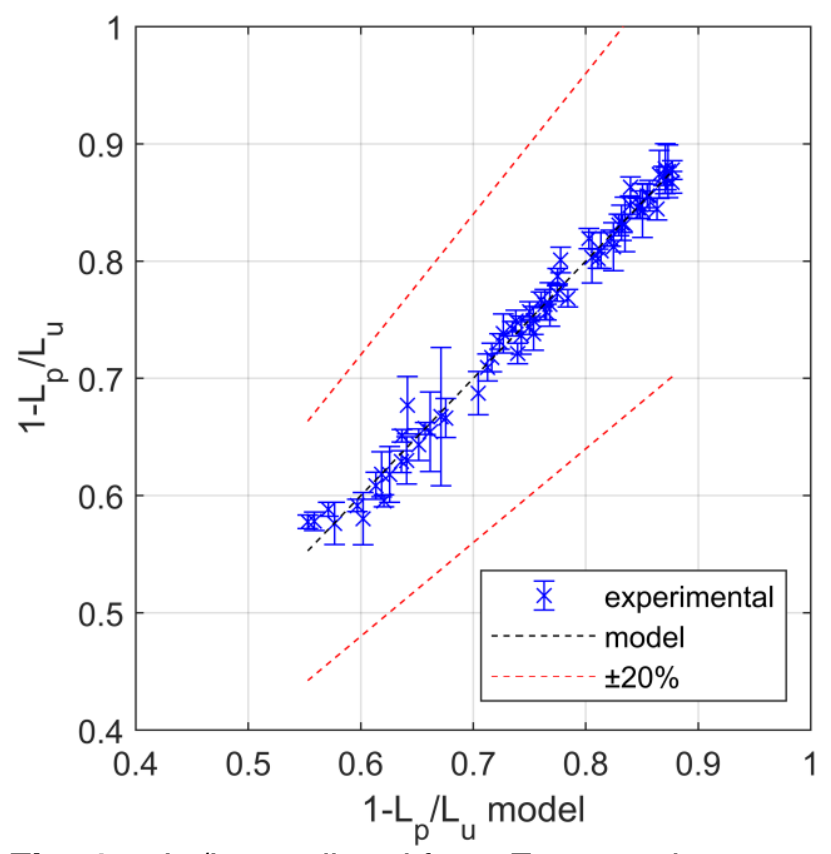

Fig. 4. $1-L_{p} / L_{u}$ predicted from Eq. 2 against experimental results with $20 \%$ bands for all cases studied.

In segmented flow, the unit length $\left(L_{u}\right)$, defined as the length of a plug and a slug, is an important variable. In Eq. 3, derived from Eqs. 1 and 2, $L_{u} / d$ is given as a function of $Q_{d} / Q_{T}$, $\mu_{\mathrm{d}} / \mu_{\mathrm{c}}, \mathrm{Ca}_{\mathrm{c}}$ and $R e_{\mathrm{d}} / \mathrm{Ca}_{\mathrm{c}}$. According to Eq. 3, $\mathrm{L}_{\mathrm{u}} / \mathrm{d}$ decreases as $\mathrm{Q}_{\mathrm{d}} / \mathrm{Q}_{\mathrm{T}}, \mu_{\mathrm{d}} / \mu_{\mathrm{c}}$, or $C a_{\mathrm{c}}$ increase, while it depends slightly on $\mathrm{Re}_{d} / \mathrm{Ca}_{\mathrm{c}}$ as the exponent is only 0.099 . The comparison between 
the predictions of Eq. 3 and the experimental data, as shown in Fig. 5, is generally good. However, there are cases where the errors of the regressions in Table 2 are combined and the prediction can be poor.

$$
\frac{L_{u}}{d}=\left(\frac{R e_{c}}{C a_{c}}\right)^{0.099} \frac{0.077}{\left(\frac{Q_{c}}{Q_{T}}\right)^{0.872}\left(\frac{\mu_{d}}{\mu_{c}}\right)^{0.36} \mathrm{Ca}_{c}^{0.28}-0.44\left(\frac{Q_{c}}{Q_{T}}\right)^{2.05}\left(\frac{\mu_{d}}{\mu_{c}}\right)^{0.26} \mathrm{Ca}_{c}^{0.15}}
$$

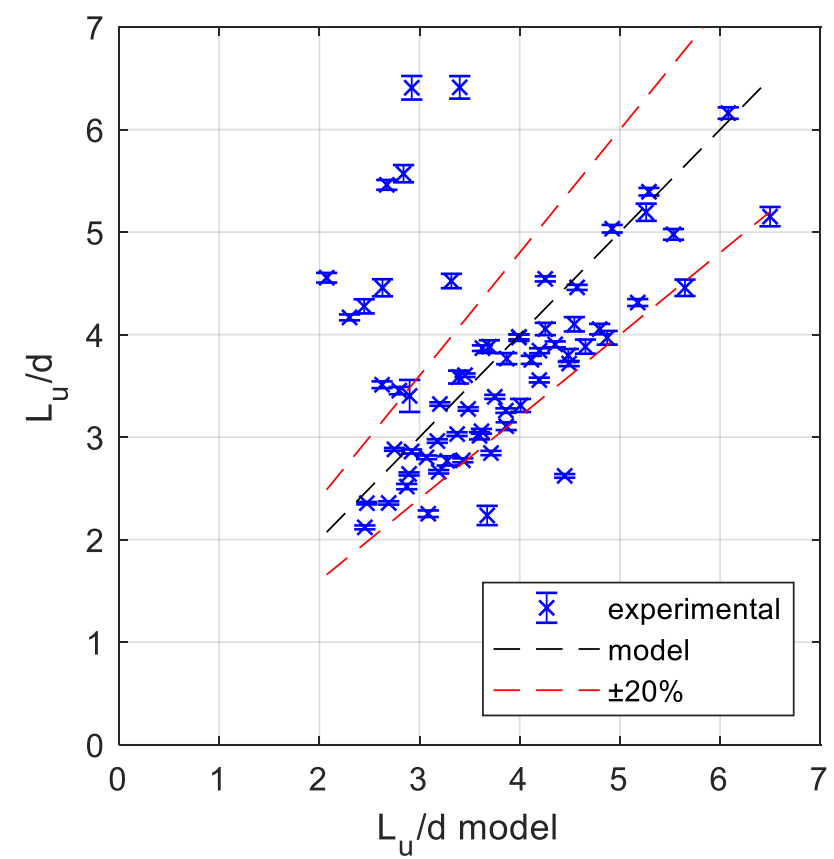

Fig. 5. $\mathrm{L}_{u} / \mathrm{d}$ predicted from Eq. 3 against experimental results with $20 \%$ bands for all cases studied.

The effect of changing the organic phase is not clear only by analysing Eq. 3 because changing the organic phase changes several properties simultaneously (see Table 1). Fig. 6 exemplifies the effect of changing the organic phase by plotting $\mathrm{L}_{u} / d$ against $\mathrm{Ca}_{c}$ under similar flow conditions (same diameter, flow rate ratio and range of mixture velocities) for both organic phases used. Some of the flow conditions shown in Fig. 6 are further analysed in the pressure drop and mass transfer sections (See Figs. 8, 9, and 11). For a given $\mathrm{Ca}_{c}, \mathrm{~L}_{u} / \mathrm{d}$ is lower for the less viscous continuous phase (TBP $30 \%$ in this case). 


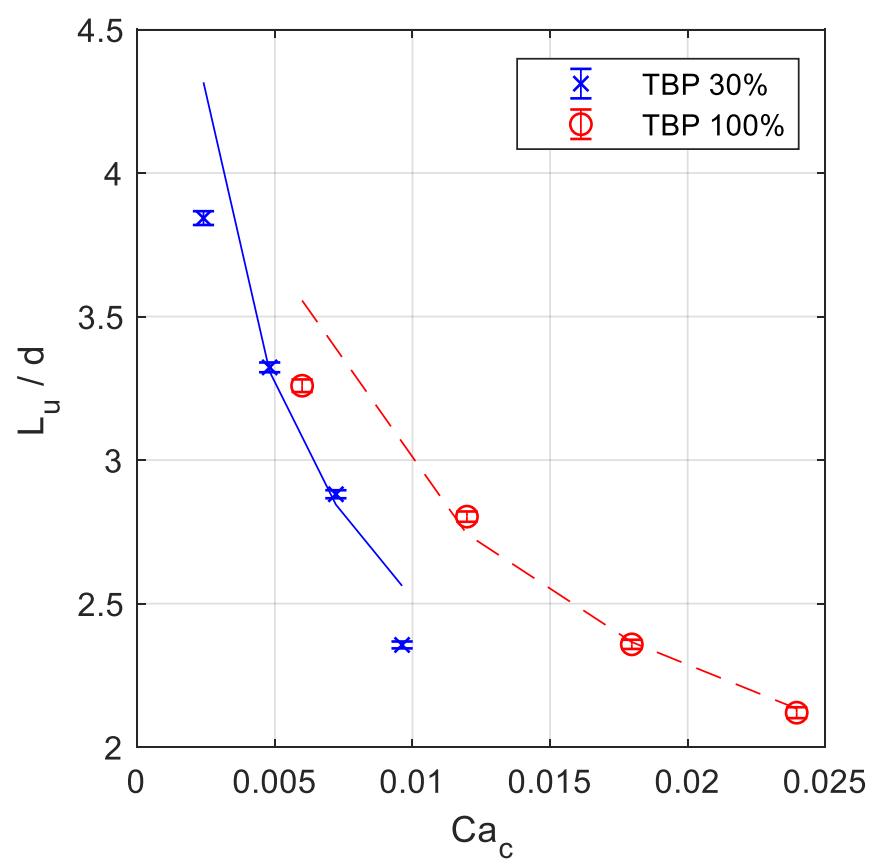

Fig. 6. Effect of changing the organic phase between TBP $30 \%$ and TBP $100 \%$ on $L_{u} / d$ with experimental and predicted values using Eq. 3. Similar flow conditions are plotted for both organic phases $\left(Q_{c} / Q_{T}=0.5, d=2 \mathrm{~mm}\right.$, and $\left.u_{m i x}=[1.06,2.12,3.18,4.24] \mathrm{cm} \mathrm{s}^{-1}\right)$. The TBP $30 \%$ cases have $\operatorname{Re}_{\mathrm{c}} / \mathrm{Ca}_{\mathrm{c}}=3301$ and $\mu_{\mathrm{d}} / \mu_{\mathrm{c}}=0.426$ (continuous line). The TBP $100 \%$ cases have $\mathrm{Re}_{\mathrm{c}} / \mathrm{Ca}_{\mathrm{c}}=792$ and $\mu_{\mathrm{d}} / \mu_{\mathrm{c}}=0.216$ (dashed line).

A number of correlations have previously been given in the literature for $L_{p} / d$ in liquidliquid segmented flows. They usually take a power law form and use three or four parameters. These correlations are summarised in Table 3 and take the form of Eq. 4 . The correlations by Gartstecki et al. and Prilezski et al. have an additive constant $\left(\mathrm{c}_{1}\right)$ in Eq. 4. The power-law term includes the effect of the flow rate ratio $\left(\left(Q_{d} / Q_{c}\right)^{c 3}\right)$, the capillary number $\left(\mathrm{Ca}_{c}{ }^{c 4}\right)$ (which includes the effect of velocity), and another factor which may account for the effects of viscosities and of the channel diameter $\left(c_{2}\right)$. For gas-liquid systems, Haase reviewed several $L_{p} / d$ correlations $[16]$.

$$
\frac{L_{p}}{d}=c_{1}+c_{2}\left(\frac{Q_{d}}{Q_{c}}\right)^{C_{3}} \mathrm{Ca}_{c} c_{4}
$$

Table 3 Summary of constants and adjustable parameters for Eq. 4 according to published correlations for liquid-liquid systems. $d_{h}$ is the hydraulic diameter of the square channels.

\begin{tabular}{|c|c|c|c|c|c|}
\hline Reference & Notes & $\mathrm{c}_{1}$ & $\mathrm{C}_{2}$ & $\mathrm{C}_{3}$ & $\mathrm{C}_{4}$ \\
\hline $\begin{array}{c}\text { Garstecki et al. } \\
{[9]}\end{array}$ & $\begin{array}{c}\text { T-junction } \\
\text { Rectangular } \\
\text { section } \\
\mathrm{d}_{\mathrm{h}}=40-88 \mu \mathrm{m}\end{array}$ & 1 & Parameter & 1 & 0 \\
\hline
\end{tabular}




\begin{tabular}{|c|c|c|c|c|c|}
\hline $\begin{array}{c}\text { Fu et al. } \\
\text { [10] }\end{array}$ & $\begin{array}{c}\text { Flow focusing } \\
\text { inlet } \\
\text { Rectangular } \\
\text { section } \\
\mathrm{d}_{\mathrm{h}}=400-600 \mu \mathrm{m}\end{array}$ & 0 & $\begin{array}{c}\text { Parameter } \\
0.72 \text { for } \\
L_{p} / d<2.35 \\
0.30 \text { for } \\
L_{p} / d>2.35\end{array}$ & $\begin{array}{c}\text { Parameter } \\
0.14 \text { for } \\
L_{p} / d<2.35 \\
0.23 \text { for } \\
L_{p} / d>2.35\end{array}$ & $\begin{array}{c}\text { Parameter } \\
-0.19 \text { for } \\
L_{p} / d<2.35 \\
-0.42 \text { for } \\
L_{p} / d>2.35\end{array}$ \\
\hline $\begin{array}{c}\text { Prilezski et al. } \\
\text { [11] }\end{array}$ & $\begin{array}{l}\text { T-junction } \\
\text { Rectangular } \\
\text { channels } \\
d_{h}=33 \mu \mathrm{m}\end{array}$ & $\begin{array}{c}\text { Parameter } \\
1.44\end{array}$ & $\begin{array}{c}\mathrm{f}\left(\mu_{\mathrm{d}}\right) \\
1.72 / \mu_{\mathrm{d}}\end{array}$ & 1 & 0 \\
\hline $\begin{array}{l}\text { Li \& Angeli } \\
\text { [8] }\end{array}$ & $\begin{array}{c}\text { T-junction } \\
\text { Circular section } \\
d=200-500 \mu \mathrm{m}\end{array}$ & 0 & $\begin{array}{c}\text { Parameter } \\
0.757 \\
\end{array}$ & $\begin{array}{c}\text { Parameter } \\
0.512 \\
\end{array}$ & $\begin{array}{c}\text { Parameter } \\
-0.273 \\
\end{array}$ \\
\hline $\begin{array}{c}\text { Tsaoulidis \& } \\
\text { Angeli } \\
\text { [12] }\end{array}$ & $\begin{array}{c}\text { T-junction } \\
\text { Circular section } \\
\mathrm{d}=0.5-2 \mathrm{~mm}\end{array}$ & 0 & $\begin{array}{c}\mathrm{f}\left(\mathrm{Re}_{\mathrm{c}} / \mathrm{Ca}_{\mathrm{c}}\right) \\
\\
2.2882 \times \\
\left(\mathrm{Re}_{\mathrm{c}} / \mathrm{Ca}_{\mathrm{c}}\right)^{-0.5017}\end{array}$ & $\begin{array}{c}u_{c} / u_{\text {mix }} \text { instead of } \\
Q_{d} / Q_{c} \\
\left(u_{c} / u_{\text {mix }}\right)^{-0.9634}\end{array}$ & $\begin{array}{c}\text { Parameter } \\
-0.2289\end{array}$ \\
\hline $\begin{array}{c}\text { Cao et al. } \\
\text { [38] }\end{array}$ & $\begin{array}{c}\text { Cross-junction } \\
\text { Rectangular } \\
\text { section } \\
d_{h}=200-600 \mu \mathrm{m} \\
\end{array}$ & 0 & $\begin{array}{c}\mathrm{f}\left(\mathrm{Re}_{\mathrm{d}}, / \mathrm{Cad}\right) \\
0.55 \times \\
\left(\mathrm{Re}_{\mathrm{d}} / \mathrm{Ca}_{\mathrm{d}}\right)^{-0.05} \\
\end{array}$ & $\begin{array}{c}\text { Parameter } \\
0.66\end{array}$ & $\begin{array}{c}\begin{array}{c}\text { Cad instead } \\
\text { of } \mathrm{Ca}_{c}\end{array} \\
-0.33 \\
\end{array}$ \\
\hline This work & $\begin{array}{c}\text { T-junction } \\
\text { Circular section } \\
\mathrm{d}=1-4 \mathrm{~mm}\end{array}$ & 0 & $\begin{array}{c}\mathrm{f}\left(\mathrm{Re}_{\mathrm{c}} / \mathrm{Ca}_{\mathrm{c}}, \mu_{\mathrm{d}} / \mu_{\mathrm{c}}\right) \\
0.0773 \times \\
\left(\mathrm{Re}_{\mathrm{c}} / \mathrm{Ca}_{\mathrm{c}}\right)^{0.099} \mathrm{x} \\
\left(\mu_{\mathrm{d}} / \mu_{\mathrm{c}}\right)^{-0.36} \\
\end{array}$ & $\begin{array}{c}Q_{c} / Q_{T} \text { instead of } \\
Q_{d} / Q_{c} \\
\left(Q_{c} / Q_{T}\right)^{-0.872}\end{array}$ & $\begin{array}{c}\text { Parameter } \\
-0.28\end{array}$ \\
\hline
\end{tabular}

The values of the adjusted parameters summarised in Table 3 differ because they are obtained for different fluids, geometries and flowrates. However, certain trends can be identified. The effect of increasing $\mathrm{Ca}_{\mathrm{c}}$, and thus $\mathrm{u}_{\text {mix }}$, is to shorten the plugs because the parameter $\mathrm{C}_{4}$ is between -0.42 and 0 (Cao et al. used the dispersed phase superficial velocity to define $\mathrm{Ca}_{d}$ but, at fixed $\mathrm{Q}_{d} / \mathrm{Q}_{\mathrm{c}}$, changes in $\mathrm{u}_{\text {mix }}$ are reflected in the variations of $\left.\mathrm{Ca}_{d}[38]\right)$. In addition, increasing the flow rate of the dispersed phase, elongates the plugs (positive exponent in $Q_{d} / Q_{c}$ or negative exponent in $u_{c} / u_{m i x}$ or $\left.Q_{d} / Q_{T}\right)$. The dependence of $L_{p} / d$ on the channel diameter is found to have an exponent less than 0.1 for most cases except in the results by Tsaoulidis \& Angeli [12] where $L_{p} / d \propto d^{0.5}$. To the best of our knowledge, there are no available correlations for $L_{s}$ or $L_{u}$ for liquid-liquid segmented flow contactors and further research would be needed in that area.

The above results will be used to derive correlations for the dispersed phase in-situ volume fraction (holdup, $\varepsilon_{d}$ ), important for calculating the equilibrium concentrations and the mass transfer coefficient. It was found that the plug and slug lengths did not vary significantly 
along the test channels. This is usually the case in liquid-liquid flows even when there is mass transfer, since the fluids are incompressible and the volumes of the plugs and slugs do not vary significantly along the channel. To estimate the dispersed phase volume fraction, the shape of the plugs is approximated by a cylinder with hemispherical caps at the end; the film thickness is thus considered constant. The holdup can be estimated from Eqs. 5 and 6 where $\varepsilon_{d}{ }^{\max }$ is an upper limit for the holdup, when the film thickness is infinitesimally small. $\varepsilon_{d}{ }^{\max }$ is, thus, only a function of plug and unit lengths, while $\varepsilon_{d}$ (Eq. 6) depends on the film thickness as well.

$$
\begin{aligned}
& \varepsilon_{\mathrm{d}}^{\max }=\frac{\mathrm{L}_{\mathrm{p}}}{\mathrm{L}_{\mathrm{u}}}-\frac{\mathrm{d}}{3 \mathrm{~L}_{\mathrm{u}}} \\
& \varepsilon_{\mathrm{d}}=\left(1-2 \frac{\delta}{\mathrm{d}}\right)^{2} \varepsilon_{\mathrm{d}}^{\max }
\end{aligned}
$$

In Eq. $6, \delta$ is the film thickness, which can be calculated from correlations or measured; it was not obtained in this study as it would require images with higher resolution to the ones used. For the range of conditions and the properties of the liquids used, the correlation by Mac Giolla Eain et al. can be applied (Eq. 7) [34]. The correlation is given by the authors in terms of $\mathrm{Ca}_{\mathrm{c}}\left(=\mu_{\mathrm{c}} \times \mathrm{u}_{\mathrm{mix}} / \mathrm{Y}\right)$ and $\mathrm{We}_{\mathrm{c}}\left(=\mathrm{Re}_{\mathrm{c}} \times \mathrm{Ca}_{\mathrm{c}}=\rho_{\mathrm{c}} \times \mathrm{u}_{\mathrm{mix}}{ }^{2} \times \mathrm{d} / \mathrm{Y}\right)$ and is also written in Eq. 7 in terms of $\mathrm{Ca}_{\mathrm{c}}$ and $\operatorname{Re}_{\mathrm{c}} / \mathrm{Ca}_{\mathrm{c}}\left(=\rho_{\mathrm{c}} \times \gamma \times \mathrm{d} / \mu_{\mathrm{c}}{ }^{2}\right)$ to show explicitly the effect of velocity. The factor $(1-2 \delta / d)^{2}$ that appears in Eq. 6 varies between 0.83 and 0.95 for all the experimental conditions tested.

$$
\frac{2 \delta}{\mathrm{d}}=0.35 \mathrm{Ca}_{\mathrm{c}}^{0.354} \mathrm{We}_{\mathrm{c}}^{0.097}=0.35 \mathrm{Ca}_{\mathrm{c}}^{0.548}\left(\frac{\mathrm{Re}_{\mathrm{c}}}{\mathrm{Ca}_{\mathrm{c}}}\right)^{0.097}
$$

The specific interfacial area (a), defined as the interfacial area per unit volume of the contactor, is also used in the calculation of the mass transfer coefficient and is not easily measured. Considering the plug shape discussed above, the specific interfacial area can be calculated from Eqs. 8 and 9. As with the holdup, $a^{\max } \times d$ is derived considering infinitesimally small film thickness and depends only on the plug and slug lengths while a (Eq. 9) requires the film thickness as well. For the conditions studied the factor $(1-2 \delta / d)$ varies between 0.91 and 0.97 . 


$$
\begin{aligned}
& a^{\max } \times d=4 \frac{L_{p}}{L_{u}} \\
& a=\left(1-2 \frac{\delta}{d}\right) a^{\max }
\end{aligned}
$$

Eqs. 1 and 2 can be substituted in Eqs. 5 and 8 to provide estimations for $\varepsilon_{d}{ }^{\max }$ and $a^{\max }$ (Eqs. 10 and 11). These equations have multiple terms but the overall effect of each dimensionless number can still be analysed. In the case of the maximum holdup, $Q_{c} / Q_{T}, \mu_{d} / \mu_{c}$, and $C a_{c}$ correlate negatively, while $\mathrm{Re}_{\mathrm{c}} / \mathrm{Ca}_{\mathrm{c}}$ correlates positively. On the other hand, $\mathrm{a}^{\max } \times \mathrm{d}$ increases with $\mathrm{Ca}_{\mathrm{c}}$ and $\mu_{\mathrm{d}} / \mu_{\mathrm{c}}$ but decreases as $\mathrm{Q}_{\mathrm{d}} \mathrm{Q}_{\mathrm{T}}$ increases. The only term in both equations that depends on the channel size is $\mathrm{Re}_{c} / \mathrm{Ca}_{c} ; \varepsilon_{d}{ }^{\text {max }}$ has a small and positive dependence on $\mathrm{d}$ while $a_{\max } \times d$ is independent of the channel size.

$$
\begin{aligned}
& \varepsilon_{\mathrm{d}}^{\max }=1-4.3\left(\frac{\mathrm{Q}_{\mathrm{c}}}{\mathrm{Q}_{\mathrm{T}}}\right)^{0.872}\left(\frac{\mu_{\mathrm{d}}}{\mu_{\mathrm{c}}}\right)^{0.36}\left(\frac{\mathrm{Re}_{\mathrm{c}}}{\mathrm{Ca}_{\mathrm{c}}}\right)^{-0.099} \mathrm{Ca}_{\mathrm{c}}^{-0.280}-0.44\left(\frac{\mathrm{Q}_{\mathrm{c}}}{\mathrm{Q}_{\mathrm{T}}}\right)^{1.18}\left(\frac{\mu_{\mathrm{d}}}{\mu_{\mathrm{c}}}\right)^{-0.099} \mathrm{Ca}_{\mathrm{c}}^{-0.130}+ \\
& 1.89\left(\frac{\mathrm{Q}_{\mathrm{c}}}{\mathrm{Q}_{\mathrm{T}}}\right)^{1.03}\left(\frac{\mu_{\mathrm{d}}}{\mu_{\mathrm{c}}}\right)^{0.26}\left(\frac{\mathrm{Re}_{\mathrm{c}}}{\mathrm{Ca}_{\mathrm{c}}}\right)^{-0.099} \mathrm{Ca}_{\mathrm{c}}^{-0.41} \\
& \mathrm{a}^{\max } \times \mathrm{d}=4-1.8\left(\frac{\mathrm{Q}_{\mathrm{c}}}{\mathrm{Q}_{\mathrm{T}}}\right)^{1.18}\left(\frac{\mu_{\mathrm{d}}}{\mu_{\mathrm{c}}}\right)^{-0.099} \mathrm{Ca}_{\mathrm{c}}^{-0.130}
\end{aligned}
$$

\subsection{Pressure gradient in segmented flow}

Pressure drop is an important parameter for the design of segmented flow contactors that can be used to calculate pumping requirements, to design flow distributors for scale-out ([39]) and even to estimate plug or slug lengths, as proposed by Kreutzer et al. [17], which is particularly useful in the case of non-transparent channels.

Bretherton first developed a model for the calculation of pressure drop during the flow of elongated bubbles in tubes [40]. Kreutzer al. suggested a model where the pressure drop combining the pressure dorp in the slug and the plug regions. In the slug region pressure drop is calculated from the Hagen-Poiseuille equation for laminar, fully developed flow, while in the 
plug region it is calculated as a function of $L_{s} / d$ and $R e / C a$ based on the correlation by Bretherton [17]. Jovanovic et al. further developed the pressure drop model to include contributions from the dispersed phase, the continuous phase and the interface [18]. The model, however, depends on a large number of variables and requires the film thickness and the plug velocity as inputs. More recently, Mac Giolla Eain et al. reviewed the available literature and proposed a new model based on previous correlations and on experimental data [19]. They found that the model by Kreutzer et al. had large errors while the model by Jovanovic et al. systemically underestimated the experimental results in liquid-liquid segmented flows. The model proposed by Mac Giolla Eain et al. assumes that the pressure drop in the slug region follows the Hagen-Poiseuille law while the pressure drop in the plug region depends on $Q_{c} / Q_{T}, C a, L_{s} / d$ and $A^{\prime} / A_{p}$ ' (cross-sectional area of the channel over crosssectional area of the plug). Kreutzer et al. [17] and Mac Giolla Eain et al. [19] obtained their results using a single channel size each (2.3 and $1.59 \mathrm{~mm}$ respectively) while Jovanovic used two small channel sizes in a relatively narrow range $(0.248$ and $0.498 \mathrm{~mm})$ [18]; this indicates that there is a need for a pressure drop model to include large diameters.

Previous numerical simulations have shown that in plug flow in circular channels the pressure profile followed the Hagen-Poiseuille equation, interrupted by periodic increases when plugs were present [8]. The periodicity of the pressure variation is used here to develop a new pressure gradient model for segmented flow contactors. In the model, the average pressure gradient in a tube with length $L((\Delta p / L)$ average $)$ with a fully developed segmented flow, is modelled as a periodic function with a period of $L_{u}$ (Eq. 12) [41].

$$
\left(\frac{\Delta \mathrm{p}}{\mathrm{L}}\right)_{\text {average }}=\frac{\int_{0}^{\mathrm{L}}\left(\frac{\Delta \mathrm{p}}{\mathrm{L}}\right) \mathrm{dx}}{\int_{0}^{\mathrm{L}} \mathrm{dx}}=\frac{1}{\mathrm{~L}_{\mathrm{u}}} \int_{0}^{\mathrm{L}_{\mathrm{u}}}\left(\frac{\Delta \mathrm{p}}{\mathrm{L}}\right) \mathrm{dx}
$$

The full derivation of the two-phase pressure drop model is shown in the Appendix. The pressure gradient in a unit cell is composed of contributions from the plug and the slug sections (Eq. 13). The pressure drop in the slug is calculated from the Hagen-Poiseuille equation. The 
contribution from the plug section $\left((\Delta \mathrm{p} / \mathrm{L})_{\mathrm{d}}\right)$ is unknown and captures the complex pressure losses in this region (including frictional and Laplace effects)

$$
\left(\frac{\Delta \mathrm{p}}{\mathrm{L}}\right)_{\text {average }}=\frac{32 \mu_{\mathrm{c}} \mathrm{u}_{\operatorname{mix}}}{\mathrm{d}^{2}}\left(1-\frac{\mathrm{L}_{\mathrm{p}}}{\mathrm{L}_{\mathrm{u}}}\right)+\left(\frac{\Delta \mathrm{p}}{\mathrm{L}}\right)_{\mathrm{d}} \frac{\mathrm{L}_{\mathrm{p}}}{\mathrm{L}_{\mathrm{u}}}
$$

Eq. 13 can be written in dimensionless form (Eq. 14) with the definition of an overall friction factor $\left(f_{u}=(\Delta p / L)_{\text {average }} \times d /\left(\rho_{c} \times u_{\text {mix }}{ }^{2}\right)\right)$, a dispersed phase friction factor $\left(f_{d}=(\Delta p / L)_{d} \times d /\left(\rho_{d} \times u_{m i x}{ }^{2}\right)\right)$, and a dispersed phase Reynolds number $\left(R e_{d}=\rho_{d} \times u_{\text {mix }} \times d / \mu_{d}\right)$. These friction factors are not to be confused with the Fanning friction factor.

$$
f_{u} \operatorname{Re}_{c}=32\left(1-\frac{L_{p}}{L_{u}}\right)+f_{d} \operatorname{Re}_{d} \frac{L_{p}}{L_{u}} \frac{\mu_{d}}{\mu_{c}}
$$

Eqs. 13 and 14 have one degree of freedom and an additional equation is needed. From the experimental data, the following empirical correlation was obtained for $f_{d}$ :

$$
\mathrm{f}_{\mathrm{d}}=0.888 \times \mathrm{f}_{\mathrm{u}}^{1.046}
$$

This correlation has an $\mathrm{R}^{2}$ of 0.995 for the conditions presented in Section 2 . The coefficient and exponent have $95 \%$ confidence intervals of $2.3 \%$ and $1.6 \%$, respectively. By substituting Eq. 15 in Eq. 14, the following equation is obtained:

$$
\mathrm{f}_{\mathrm{u}} \operatorname{Re}_{\mathrm{c}}=32\left(1-\frac{\mathrm{L}_{\mathrm{p}}}{\mathrm{L}_{\mathrm{u}}}\right)+0.888 \mathrm{f}_{\mathrm{u}}^{1.046} \operatorname{Re}_{\mathrm{d}} \frac{\mathrm{L}_{\mathrm{p}}}{\mathrm{L}_{\mathrm{u}}} \frac{\mu_{\mathrm{d}}}{\mu_{\mathrm{c}}}
$$




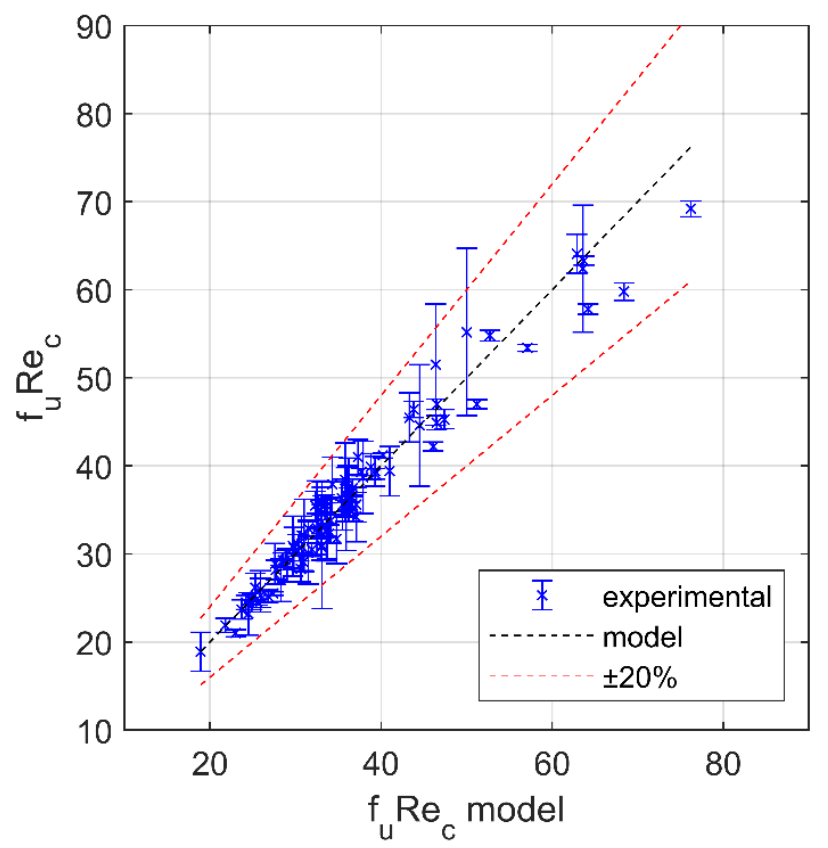

Fig. 7. $f_{u} R e_{c}$ predicted from Eq. 16 and experimental results with $20 \%$ bands for all cases studied.

The experimental results are compared to the model in Fig. 7. The model described by Eq. 16 is implicit with respect to $f_{u}$ and must be solved numerically given the Reynolds numbers for both phases, the length fraction of the plug and the viscosity ratio. This pressure drop model does not include the plug velocity or the film thickness. Most of the other models show the capillary number explicitly. The model in Eq. 16 includes the dependence on the capillary number implicitly in the length fraction of the plug (Eq. 2). Eq. 16 accurately predicts the pressure drop for the ranges of $Q_{d} / Q_{T}, \mu_{c} / \mu_{d}, C a_{c}$, and $R_{c}$ in Table 2. Different values of the coefficient and exponent in the calculation of the overall friction factor in Eq. 15 would be needed for conditions outside these values or for different inlet or channel geometries.

The effects of the test section diameter and of the operational variables on the pressure gradient are shown in Fig. 8. The average pressure gradient is proportional to $d^{-2}, u_{\text {mix }}{ }^{1}$, and $\mu_{c}{ }^{1}$. In Eq. 16, the effect of the flow rate ratio is only captured in the plug length fraction, which strongly depends on $Q_{d} Q_{T}$. Since the organic (continuous) phases are more viscous than the aqueous (dispersed) phase, reducing $Q_{d} / Q_{T}$ results in lower pressure gradient, as shown in 
Fig. 8c. In Fig. 8c, at constant $u_{\text {mix }}$, a change in the ratio $Q_{c} / Q_{T}$ means that both $Q_{c}$ and $Q_{d}$ change.
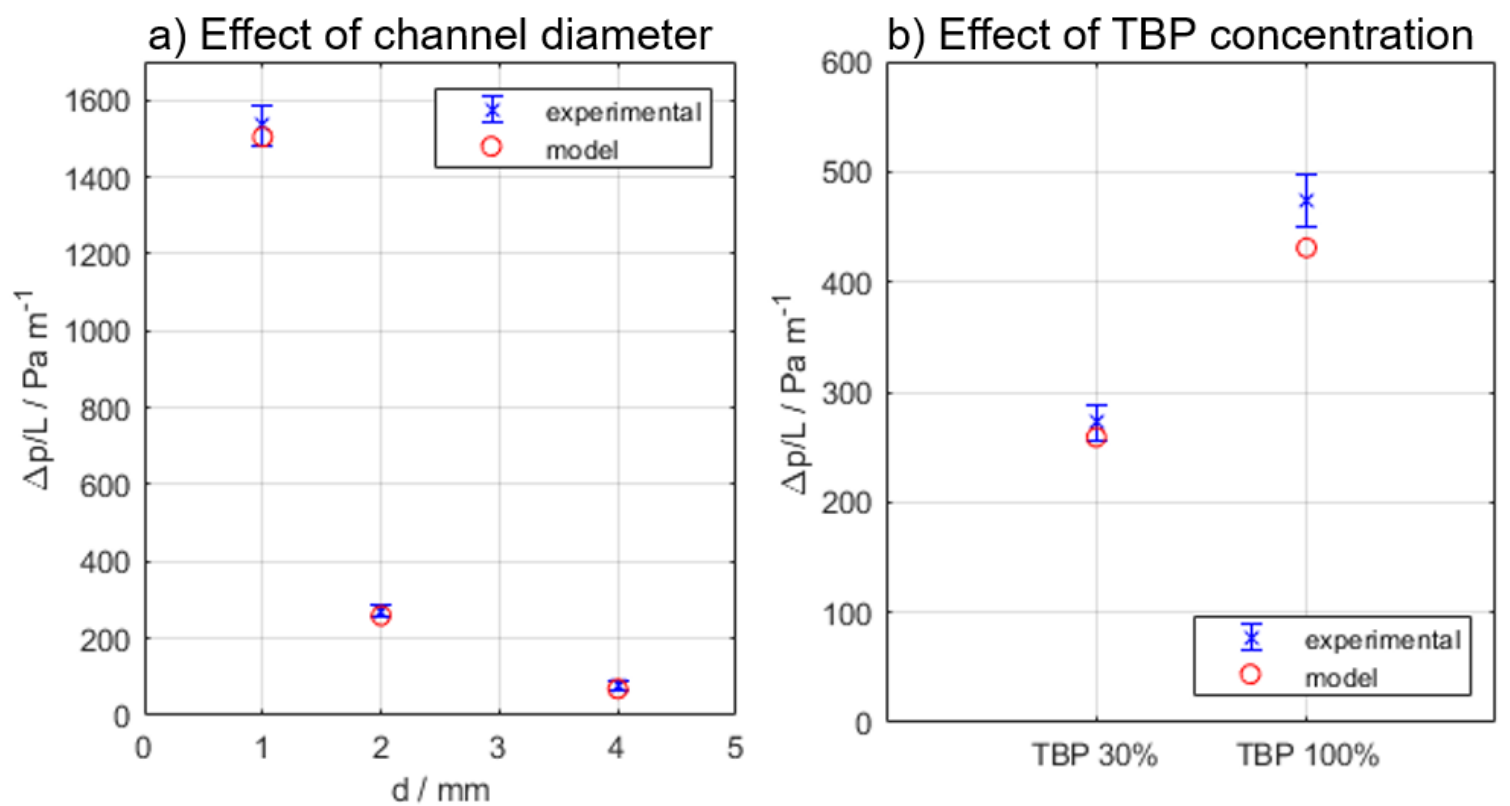

c) Effect of continuous phase
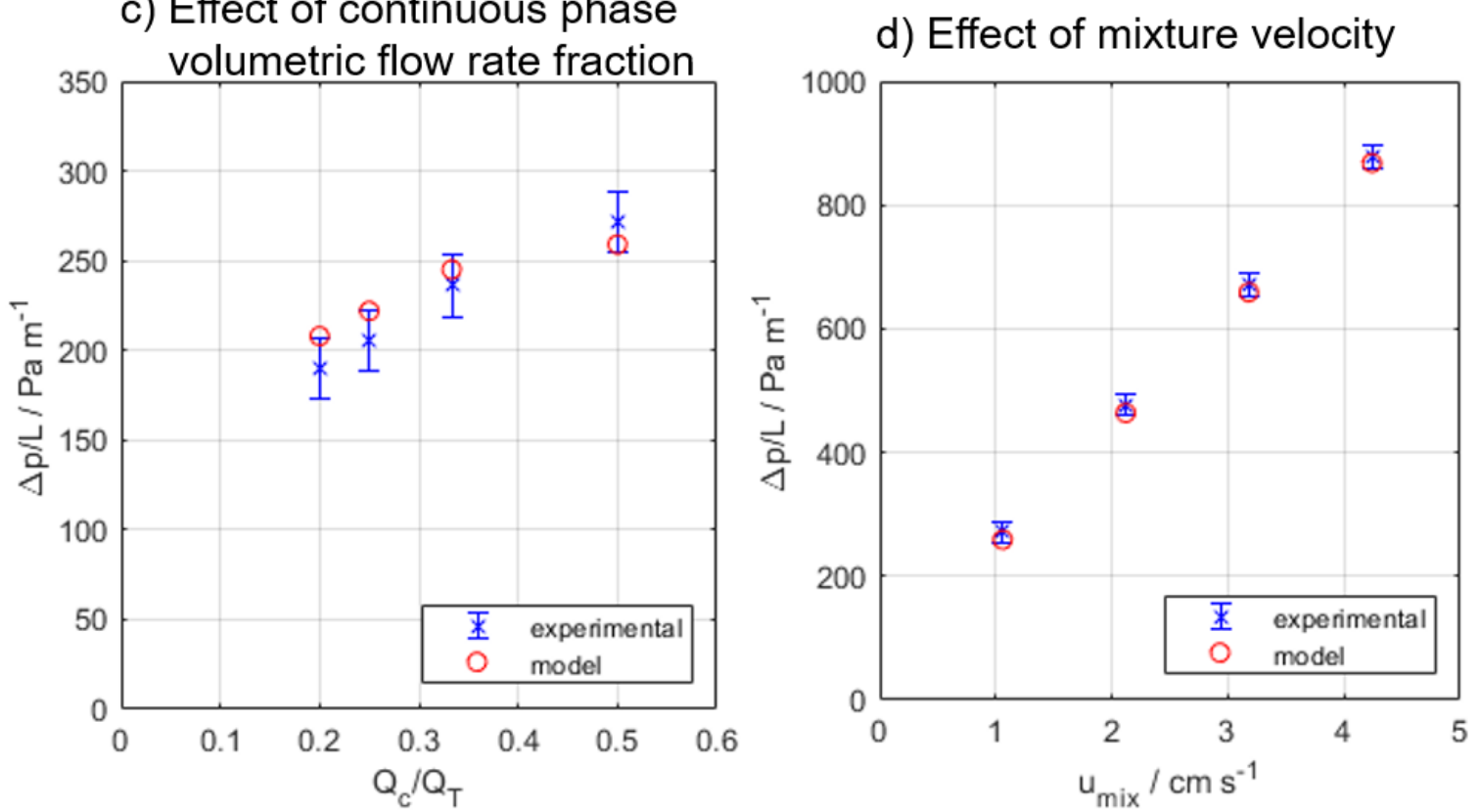

Fig. 8. Pressure gradient (experimental and calculated using Eq. 16). The base case is $d=2$ $\mathrm{mm}, \mathrm{u}_{\mathrm{mix}}=1.06 \mathrm{~cm} \mathrm{~s}^{-1}$, TBP $30 \%, \mathrm{Q}_{\mathrm{c}} / \mathrm{Q}_{\mathrm{T}}=0.500$.

The experimental results are also compared with the predictions of the models by Kreutzer et al. [17] and Jovanovic et al. [18]. The model by Kreutzer et al. is fitted with regression analysis and the adjustable parameters give $a=0.034 \pm 333 \%$ and $b=0.22 \pm 202 \%$, where the percentages correspond to $95 \%$ confidence intervals. Kreutzer et al. had reported values of 0.17 and 0.07 for $a$ and 0.33 for $b$ [17]. The models by Jovanovic et al. are adjusted 
by fitting the curvature parameter $(\mathrm{J})$. The best fits for $\mathrm{J}$ are $5.1 \pm 60 \%$ and $5.9 \pm 51 \%$ (the percentages correspond to $95 \%$ confidence intervals) for the stagnant film and the moving film models, respectively (Jovanovic et al. reported a value of 7.16 [18]). In order to use the model by Jovanovic et al., the film thickness is estimated from the model proposed by Mac Giolla Eain et al. [34] (Eq. 7) while $u_{p} / u_{\text {mix }}$ is estimated from the correlation by Abiev et al. [15]. Neither of these models provides a good fit of the experimental data, while the model by Jovanovic et al. requires, in addition, estimations of $\delta$ and $u_{p}$ which have large uncertainties associated.

The plug length fraction $\left(L_{p} / L_{u}\right)$ can be directly calculated from Eq. 16 given the pressure gradient, the properties of the fluids, the channel diameter, the flow rate ratio of the two phases, and the mixture velocity. Therefore, the pressure gradient can be used to estimate $a^{\max } \times d$ using Eq. 8. However the pressure gradient measurement alone is not sufficient to predict both $L_{p} / d$ and $L_{u} / d$ simultaneously and an additional measurement would be necessary. A second measurement could be the plug formation frequency obtained by analysing the pressure drop signal, as proposed by Miyabayashi et al. [42].

\section{3 $\mathrm{U}(\mathrm{VI})$ extraction and mass transfer in segmented flow contactors}

\subsubsection{Analysis of operation and design variables on extraction efficiency}

The extraction results are presented here for the cases described in Section 2. A base case is studied first $\left(d=2 \mathrm{~mm}, u_{\text {mix }}=1.06 \mathrm{~cm} \mathrm{~s}^{-1}\right.$, TBP $\left.30 \%, Q_{c} / Q_{T}=0.5\right)$ and then the effects of changes in certain parameters are investigated, including mixture velocity $\left(u_{\text {mix }}=4.24 \mathrm{~cm} \mathrm{~s}^{-1}\right)$, channel size (1, $4 \mathrm{~mm})$, TBP concentration $(100 \%)$ and phase fraction $\left(Q_{d} / Q_{T}=0.333,0.250\right)$. The mixture velocity and internal channel diameter are considered because they impact the throughput of the process, the phase fraction determines the organic phase usage and the TBP concentration affects the equilibrium constants and the efficiency of the process.

The concentration in the aqueous phase at the exit $\left(\mathrm{C}_{a q}{ }^{\text {out }}\right)$ is measured with UV-vis spectroscopy and the extraction efficiency (\%Eff) is calculated according to Eq. 17. The 
extraction efficiency provides a measure of mass transferred relative to the maximum possible, in a certain residence time.

$$
\% \mathrm{Eff}=\frac{\mathrm{C}_{\mathrm{aq}}^{\text {out }}-\mathrm{C}_{\mathrm{aq}}^{\mathrm{in}}}{\mathrm{C}_{\mathrm{aq}}^{\mathrm{eq}}-\mathrm{C}_{\mathrm{aq}}^{\mathrm{in}}} \times 100 \%
$$

In the equation above, $\mathrm{C}_{\mathrm{aq}}{ }^{\text {eq }}$ is the equilibrium concentration of $\mathrm{U}(\mathrm{VI})$ at the conditions of the experiment. $\mathrm{C}_{\mathrm{aq}}{ }^{\text {eq }}$ is calculated as shown in Eq. 18 which uses the inlet phase flowrate ratio $\left(Q_{o r g} / Q_{a q}\right) . C_{a q}{ }^{\text {in }}$ and $C_{a q}{ }^{\text {out }}$ are the concentrations of $\mathrm{U}(\mathrm{VI})$ at the inlet and at the outlet in the aqueous phase, respectively.

$$
C_{\mathrm{aq}}^{\mathrm{eq}}=\frac{\mathrm{C}_{\mathrm{aq}}^{\mathrm{in}}}{\mathrm{D} \frac{\mathrm{Q}_{\mathrm{rg}}}{\mathrm{Qqq}_{1}}}
$$

The effect on \%Eff of increasing mixture velocity with respect to the base case, while keeping the other conditions constant, is presented in Fig. 9. For both mixture velocities, after $5 \mathrm{~s}$ residence time the extraction is above $40 \%$ efficiency. However, the base case, at low $u_{\text {mix }}$, has a slow increase in \%Eff, compared to the high $u_{\text {mix }}$ case. With the higher mixture velocity, the extraction efficiency is $>90 \%$ after 20 s residence time, while in the base case the efficiency is below $80 \%$ for the same residence time. The increase in the extraction efficiency with mixture velocity is attributed to two phenomena, the increase in interfacial area and in circulation intensity in both the plugs and the slugs. The specific interfacial areas (estimated from Eq. 9 and the imaging results for water-TBP $30 \%$ at the same flow conditions) for the low and high $u_{\text {mix }}$ cases are 1123 and $1224 \mathrm{~m}^{-1}$, respectively. In addition, as the mixture velocity increases the circulation time in the plugs decreases leading to better mixing [7]. 


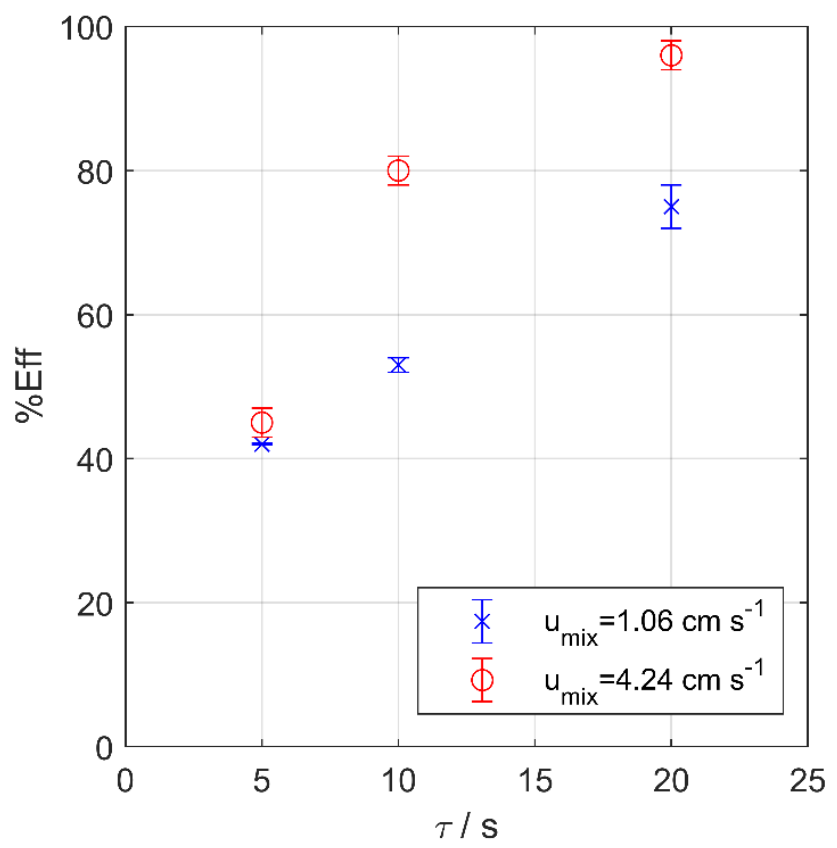

Fig. 9. Extraction efficiency against residence time for the base case $\left(d=2 \mathrm{~mm}, u_{\text {mix }}=1.06 \mathrm{~cm}\right.$ $\mathrm{s}^{-1}$, TBP $\left.30 \%, Q_{c} / Q_{T}=0.5\right)$ and for the high mixture velocity case $\left(d=2 \mathrm{~mm}, u_{\text {mix }}=4.24 \mathrm{~cm} \mathrm{~s}^{-1}\right.$, TBP 30\%, $\left.Q_{d} / Q_{T}=0.5\right)$.

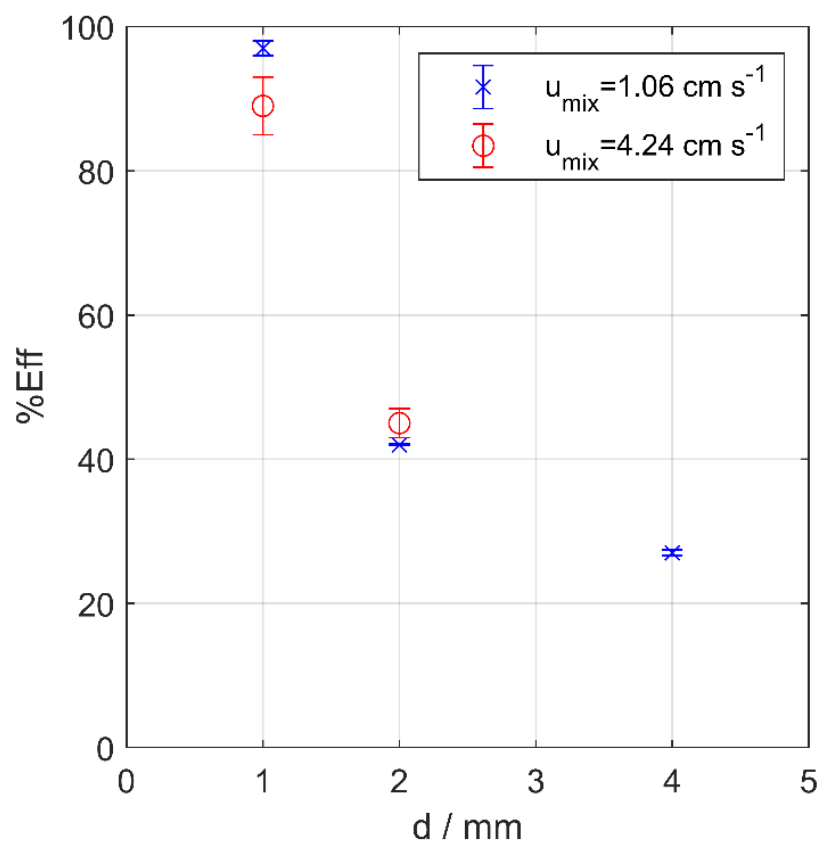

Fig. 10. Extraction efficiency (at $\mathrm{t}=5 \mathrm{~s}$ ) against internal diameter $(\mathrm{d}=1,2,4 \mathrm{~mm})$ for the base case $\left(u_{\text {mix }}=1.06 \mathrm{~cm} \mathrm{~s}^{-1}\right.$, TBP $\left.30 \%, Q_{d} / Q_{T}=0.5\right)$ and for the high mixture velocity case $\left(u_{\text {mix }}=4.24\right.$ $\mathrm{cm} \mathrm{s}^{-1}$, TBP 30\%, $\left.Q_{\mathrm{C}} / \mathrm{Q}_{\mathrm{T}}=0.5\right)$ cases.

The effect of the channel internal diameter on the extraction efficiency is presented in Fig. 10 at a residence time of $5 \mathrm{~s}$ for all cases. The separator could not operate effectively at the large mixture velocity in the $4 \mathrm{~mm}$ channel and this case is not included here. As can be seen, there is an inverse relationship between the extraction efficiency and the internal 
channel diameter. For the $1 \mathrm{~mm}$ case, extraction efficiency $>85 \%$ is achieved for both velocities. The \%Eff in the $2 \mathrm{~mm}$ channel is about half of that in the $1 \mathrm{~mm}$ channel and about double of the one in the $4 \mathrm{~mm}$ channel. The specific interfacial area follows the same relationship as \%Eff; for $u_{m i x}=1.06 \mathrm{~cm} \mathrm{~s}^{-1}$, it is equal to 2726,1123 , and $561 \mathrm{~m}^{-1}$, and for $\mathrm{u}_{\mathrm{mix}}=4.24 \mathrm{~cm} \mathrm{~s}^{-1}, 2163$, and $1224 \mathrm{~m}^{-1}$, for the 1,2 , and $4 \mathrm{~mm}$ channels respectively. In Fig. 10 , at $5 \mathrm{~s}$ residence time, in the low $u_{\text {mix }}\left(1.06 \mathrm{~cm} \mathrm{~s}^{-1}\right)$ the \%Eff is higher in the $1 \mathrm{~mm}$ channel compared to the $2 \mathrm{~mm}$ one, while at the high $u_{\text {mix }}\left(4.24 \mathrm{~cm} \mathrm{~s}^{-1}\right)$ the opposite happens. This is attributed to interfacial areas in the four cases. In the $1 \mathrm{~mm}$ channel, the low $u_{\text {mix }}$ case has interfacial area $2726 \mathrm{~m}^{-1}$, higher than the high $\mathrm{u}_{\text {mix }}$ case $\left(\mathrm{a}=2163 \mathrm{~m}^{-1}\right)$. In the $2 \mathrm{~mm}$ channel, the low $u_{\text {mix }}$ case has interfacial area equal to $1224 \mathrm{~m}^{-1}$, and the high $u_{\text {mix }}$ case has interfacial area equal to $1123 \mathrm{~m}^{-1}$. In the $2 \mathrm{~mm}$ channel, the differences in interfacial area with mixture velocity are small, reflecting the small differences in the \%Eff. 

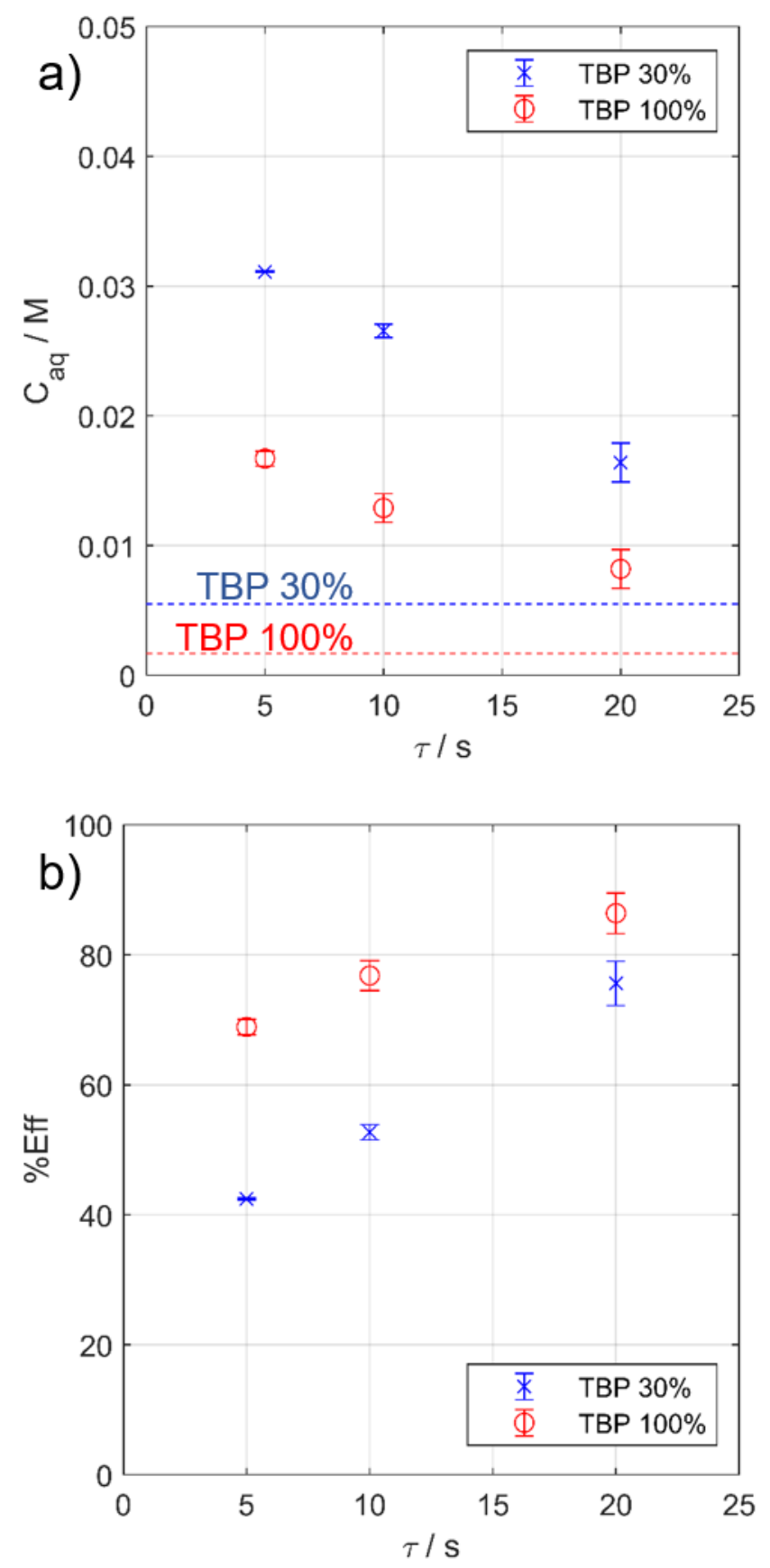

Fig. 11. Effect of TBP concentration in the organic phase on extraction. a) $U(V I)$ concentration in the aqueous phase against residence time; the dashed lines correspond to the equilibrium concentrations for each organic phase. b) Extraction efficiency against residence time. Diameter $=2 \mathrm{~mm}$, mixture velocity $=1.06 \mathrm{~cm} \mathrm{~s}^{-1}$, and phase ratio $Q_{d} Q_{T}=0.5$.

When $100 \%$ TBP is used as the organic phase, the amount of $U(V I)$ extracted is increased as can be seen in Fig. 11. Since $\mathrm{C}_{a q}$ eq is different for both cases, the results are presented in terms of $\mathrm{U}(\mathrm{VI})$ concentrations and extraction efficiency. The mass transfer in the first $5 \mathrm{~s}$ of residence time is much larger for the TBP $100 \%$ case, compared to the $30 \%$ TBP, because the driving force for the mass transfer at the inlet $\left(\mathrm{C}_{a q}{ }^{i n}-C_{a q}{ }^{e q}\right)$ is larger for the pure 
TBP case $[43,44]$. The improved extraction efficiency is attributed primarily to the difference in the driving force while the interfacial area plays practically no role in this case. The specific interfacial area in the case of $100 \%$ TBP is only $0.5 \%$ larger than in the case of $30 \%$ TBP, estimated from the water-TBP 100\% and water-TBP $30 \%$ hydrodynamic data. However, it is possible that the mass transfer coefficient is different for the two organic phases; this is considered in the next section.
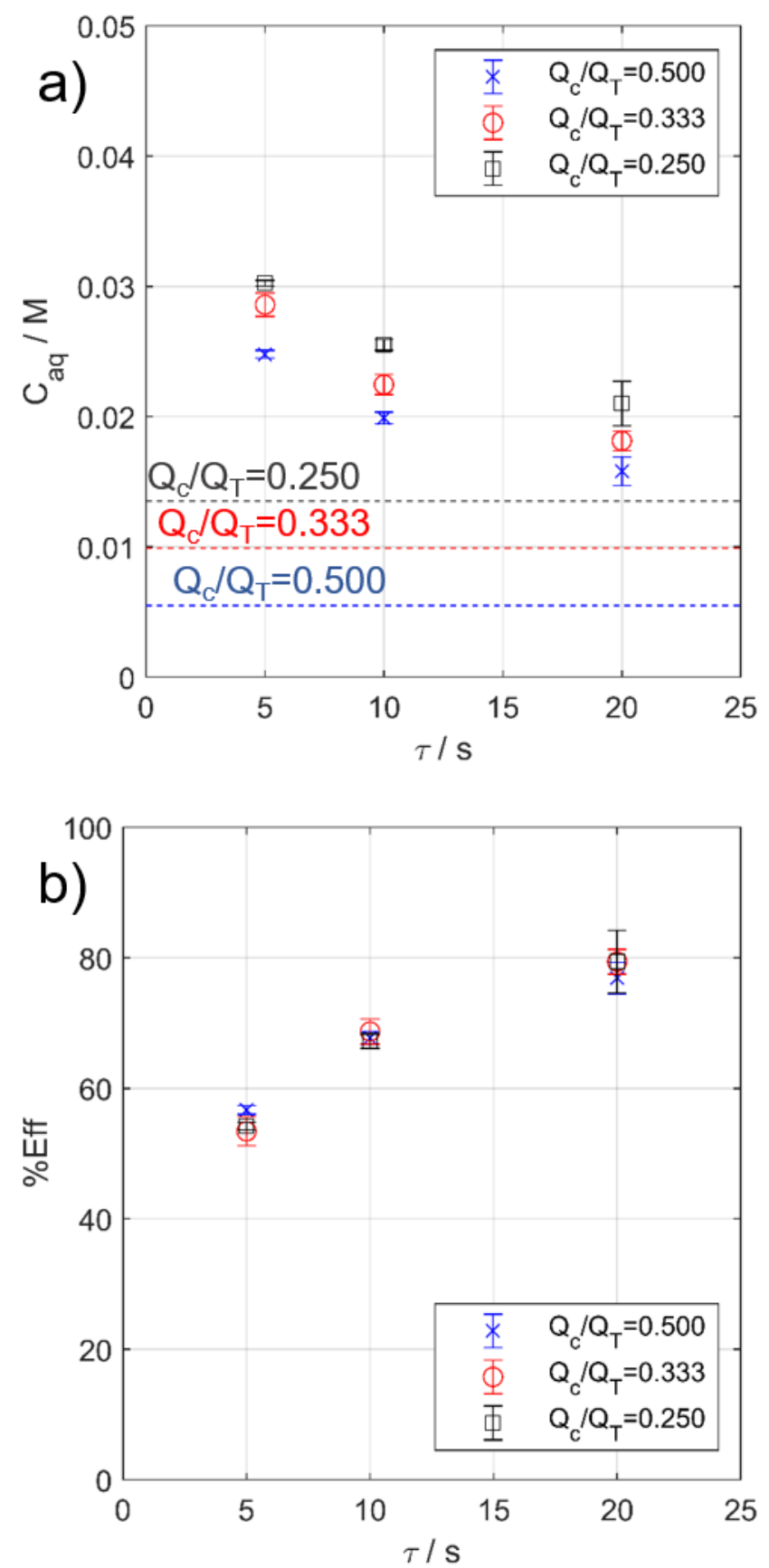

Fig. 12. Effect of the organic phase fraction on the extraction of $U(V I)$ for $Q_{d} / Q_{T}=0.500,0.333$, 0.250. a) $\mathrm{U}(\mathrm{VI})$ concentration against residence time; the horizontal lines correspond to the 
equilibrium concentrations for each organic phase fraction $\left(\mathrm{C}_{\mathrm{aq}}^{\mathrm{eq}}\right)$. b) Extraction efficiency against residence time. Diameter $=2 \mathrm{~mm}$, mixture velocity $=1.06 \mathrm{~cm} \mathrm{~s}^{-1}$, and extractant concentration = TBP $30 \%$

The effect of organic phase fraction on mass transfer is presented in Fig. 12 in terms of both $U(\mathrm{VI})$ concentration in the aqueous phase and \%Eff. The dashed lines in Fig 12 a) represent the different $C_{a q}{ }^{\text {eq }}$ for each case; higher $Q_{d} Q_{T}$ correspond to lower $C_{a q}{ }^{\text {eq }}$. For all residence times, the relative order of the concentrations is the same as that of the equilibrium concentrations. For lower $Q_{d} / Q_{T}$, the equilibrium concentration in the aqueous phase is higher and therefore the driving force for mass transfer is reduced. In terms of extraction efficiency (Fig. 12 b)), the three $Q_{d} Q_{T}$ cases are almost the same. As $Q_{c} / Q_{T}$ decreases, the interfacial area increases (specific interfacial areas are, 1123, 1422, $1592 \mathrm{~m}^{-1}$, for $\mathrm{Q}_{\mathrm{d}} / \mathrm{Q}_{\mathrm{T}}=0.500,0.333$, 0.250 , respectively) while the driving force decreases; these changes have opposite effects on the rate of mass transfer and result in similar extraction efficiencies for the three cases.

\subsubsection{Mass transfer coefficient}

The mass transfer coefficient for the aqueous phase $\left(\mathrm{K}_{\mathrm{aq}}\right)$ is calculated as follows:

$$
\mathrm{N}_{\mathrm{U}}=\frac{\mathrm{dn}_{\mathrm{U}}^{\mathrm{aq}}}{\mathrm{d} \tau} \frac{1}{\mathrm{~A}_{\mathrm{p}}}=-\mathrm{K}_{\mathrm{aq}}\left(\mathrm{C}_{\mathrm{aq}}(\tau)-\mathrm{C}_{\mathrm{aq}}^{\mathrm{eq}}\right)
$$

where $\mathrm{N}_{\mathrm{U}}$ is the flux of $\mathrm{U}(\mathrm{VI})$ across the interphase, $\mathrm{n}^{\mathrm{aq}}$ is the number of $\mathrm{U}(\mathrm{VI})$ moles in the aqueous phase, $A_{p}$ is the interfacial area and the term $C_{a q}(T)-C_{a q}$ eq is the driving force for the mass transfer. Multiplying Eq. 19 by the contactor volume to get the specific interfacial area (a) and dividing by the volume of the aqueous phase to substitute $\mathrm{n}^{\mathrm{aq}}$ with $\mathrm{C}_{\mathrm{aq}}$, Eq. 20 is obtained:

$$
\frac{\mathrm{dC}_{\mathrm{aq}}}{\mathrm{d} \tau}=-\frac{\mathrm{K}_{\mathrm{aq}} \mathrm{a}}{\varepsilon_{\mathrm{aq}}}\left(\mathrm{C}_{\mathrm{aq}}(\tau)-\mathrm{C}_{\mathrm{aq}}^{\mathrm{eq}}\right)
$$

where $\varepsilon_{\mathrm{aq}}$ is the holdup of the aqueous (dispersed) phase. By integrating between periods $\mathrm{T}_{1}$ and $\mathrm{T}_{2}$, Eq. 21 is obtained, where $\mathrm{K}_{\mathrm{aq}} \mathrm{a} / \varepsilon_{\mathrm{aq}}$ is constant with respect to residence time: 


$$
\mathrm{K}_{\mathrm{aq}}=\frac{\varepsilon_{\mathrm{aq}}}{\mathrm{a}\left(\tau_{2}-\tau_{1}\right)} \ln \left(\frac{\mathrm{C}_{\mathrm{aq}}\left(\tau_{1}\right)-\mathrm{C}_{\mathrm{aq}}^{\mathrm{eq}}}{\mathrm{C}_{\mathrm{aq}}\left(\tau_{2}\right)-C_{\mathrm{aq}}^{\mathrm{eq}}}\right)
$$

Experimental mass transfer coefficients, evaluated using Eq. 21, are presented in Table 4 for several cases studied. $\mathrm{K}_{\mathrm{aq}}$ is calculated between 5 and $20 \mathrm{~s}$ in order to characterise only the transport during segmented flow and exclude the mass transfer contributions from the inlet zone and the separator. The aqueous phase holdup (Eq. 6) and the specific interfacial area (Eq. 9) are also given for each case.

Table 4 Segmented flow mass transfer coefficient $\left(K_{a q}\right)$, specific interfacial area (a), aqueous phase holdup $\left(\varepsilon_{\mathrm{aq}}\right)$ and their products $\left(\mathrm{K}_{\mathrm{aq}} \mathrm{a}, \mathrm{K}_{\mathrm{aq}} \mathrm{a} / \varepsilon_{\mathrm{aq}}\right)$. For every case, all variables are the same as the base case, except for the stated change.

\begin{tabular}{|c|c|c|c|c|c|}
\hline Case & $\begin{array}{l}\mathrm{K}_{\mathrm{aq}} / \\
\mathrm{m} \mathrm{s}^{-1}\end{array}$ & $\begin{array}{l}\mathrm{a} / \\
\mathrm{m}^{-1}\end{array}$ & $\varepsilon_{\mathrm{aq}}$ & $\begin{array}{c}\mathrm{K}_{\mathrm{aq}} \mathrm{a} / \\
\mathrm{s}^{-1}\end{array}$ & $\begin{array}{c}\mathrm{K}_{\mathrm{aq}} \mathrm{a} / \varepsilon_{\mathrm{aq}} / \\
\mathrm{s}^{-1}\end{array}$ \\
\hline $\begin{array}{c}\text { Base case } \\
\left(\mathrm{d}=2 \mathrm{~mm}, \mathrm{u}_{\mathrm{mix}}=1.06 \mathrm{~cm} \mathrm{~s}^{-1} \text {, }\right. \\
\left.\text { TBP } 30 \%, \mathrm{Q}_{\mathrm{d}} / \mathrm{Q}_{\mathrm{T}}=0.5\right)\end{array}$ & $2.35 \times 10^{-5} \pm 16 \%$ & 1123 & 0.464 & 0.0264 & 0.0568 \\
\hline$u_{\text {mix }}=4.24 \mathrm{~cm} \mathrm{~s}^{-1}$ & $6.5 \times 10^{-5} \pm 18 \%$ & 1224 & 0.450 & 0.079 & 0.18 \\
\hline TBP $100 \%$ & $2.18 \times 10^{-5} \pm 28 \%$ & 1129 & 0.447 & 0.0246 & 0.0550 \\
\hline$Q_{d} / Q_{T}=0.333$ & $2.43 \times 10^{-5} \pm 13 \%$ & 1422 & 0.620 & 0.0346 & 0.0558 \\
\hline$Q_{C} / Q_{T}=0.250$ & $2.46 \times 10^{-5} \pm 29 \%$ & 1592 & 0.715 & 0.0391 & 0.0547 \\
\hline
\end{tabular}

The results in Table 4 show that, considering experimental uncertainties, there is no significant difference in the mass transfer coefficient $\left(\mathrm{K}_{\mathrm{aq}}\right)$ between the base, the high TBP concentration, and both organic phase fraction cases. The mass transfer coefficient is increased significantly only for the case of high mixture velocity as the mixing is improved. The internal circulation increases significantly with mixture velocity [7], thus increasing the mass transfer coefficient. 
To further investigate the mass transfer, the numerical model described in Section 2 (adapted from [24]) is used for the same cases shown in Table 4. As it was discussed before, the initial mixing of the phases at the inlet is not considered in this model. Fig. 13 shows the velocity field and concentration profile of $\mathrm{U}(\mathrm{VI})$ in the aqueous phase plug and organic phase slug for the conditions of the base case at six different times. Since the simulation follows a plug-slug unit, the time in the simulation corresponds to the residence time of the plug, not the mean residence time. The $u_{p} / u_{\text {mix }}$ ratio, calculated using a correlation by Abiev et al. [15], ranges from 1.04 to 1.11 for the five cases in Table 4; this indicates that the average residence time and the plug residence times are similar. At time 0 , the solute is homogeneously distributed in the aqueous phase plug and absent in the continuous organic phase. In the first few seconds $(t \leq 10 \mathrm{~s})$, the solute in the region close to the interphase inside the plug is depleted and a concentration profile, that follows the velocity profile (Fig. $13 \mathrm{a}$ ), begins to forms. This explains the fast solute depletion in the region between the caps and the plug body. At longer times $(t>10 \mathrm{~s})$, the solute in the region close to the interphase inside the plug is mostly depleted. Mass transfer continues because there is still a driving force but the solute has to diffuse from the high concentration region in the middle of the plug to the interphase. The slug (Fig. 13 c) shows similar effects as the plug at both short and long times, but with increasing concentration of $\mathrm{U}(\mathrm{VI})$ with time. It appears that at the front of the plug (Fig. $13 \mathrm{~b}$ ) some solute remains even after long residence times ( $\mathrm{see} t=30,60 \mathrm{~s}$ ); this cannot be attributed to the mass transfer phenomena but rather to the numerical solution because of the abrupt transition close to the interphase. However, since the average concentration in the plug is obtained by summing the concentration of solute across the whole volume of the plug, this discrepancy has a very minor effect on the calculated $\mathrm{C}_{\mathrm{aq}}$ and $\mathrm{K}_{\mathrm{aq}}$. 


\section{a) Direction of flow}
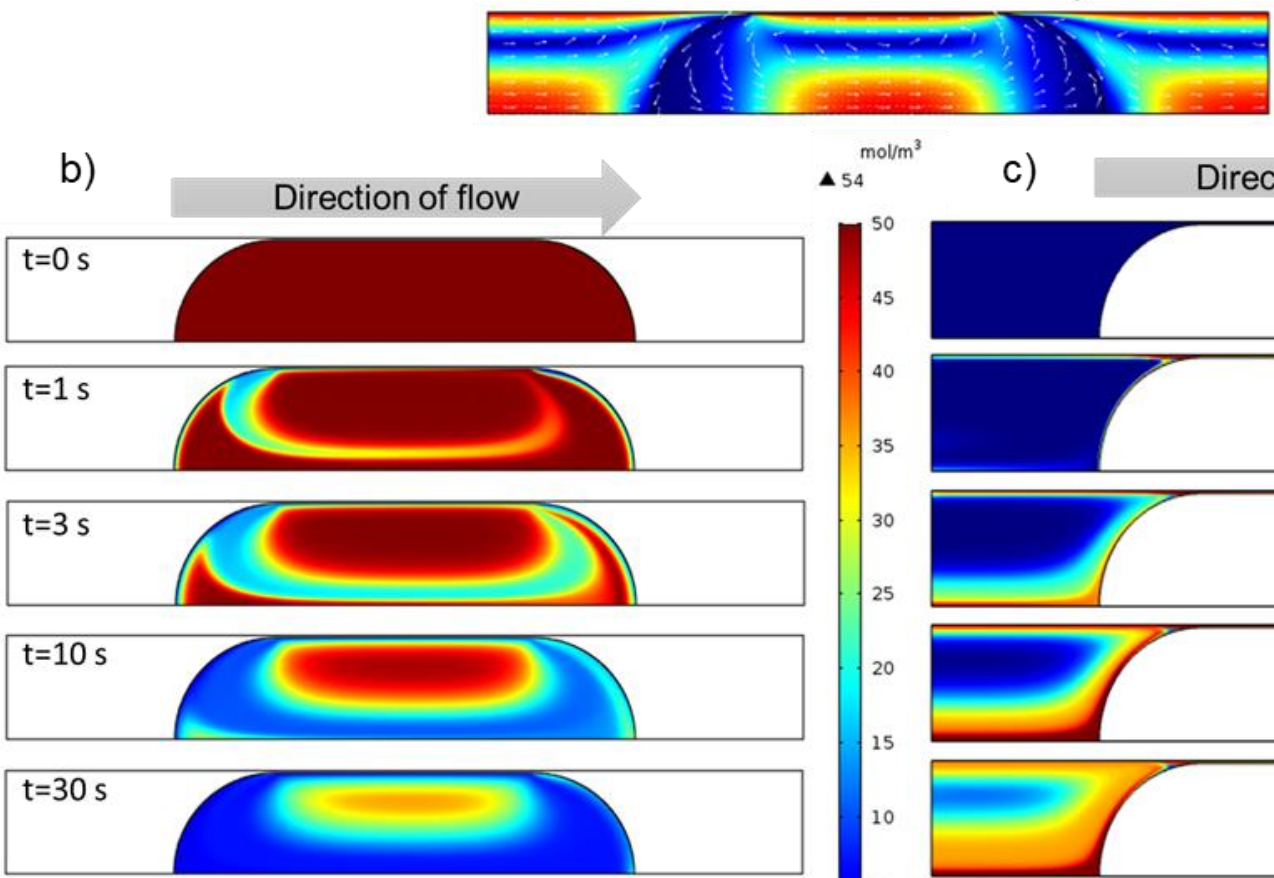

$t=60 s$

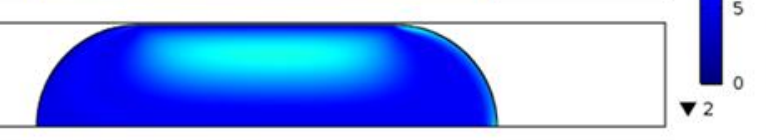

$\mathrm{mol} / \mathrm{m}^{3}$

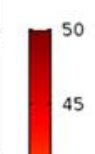

c)

Direction of flow
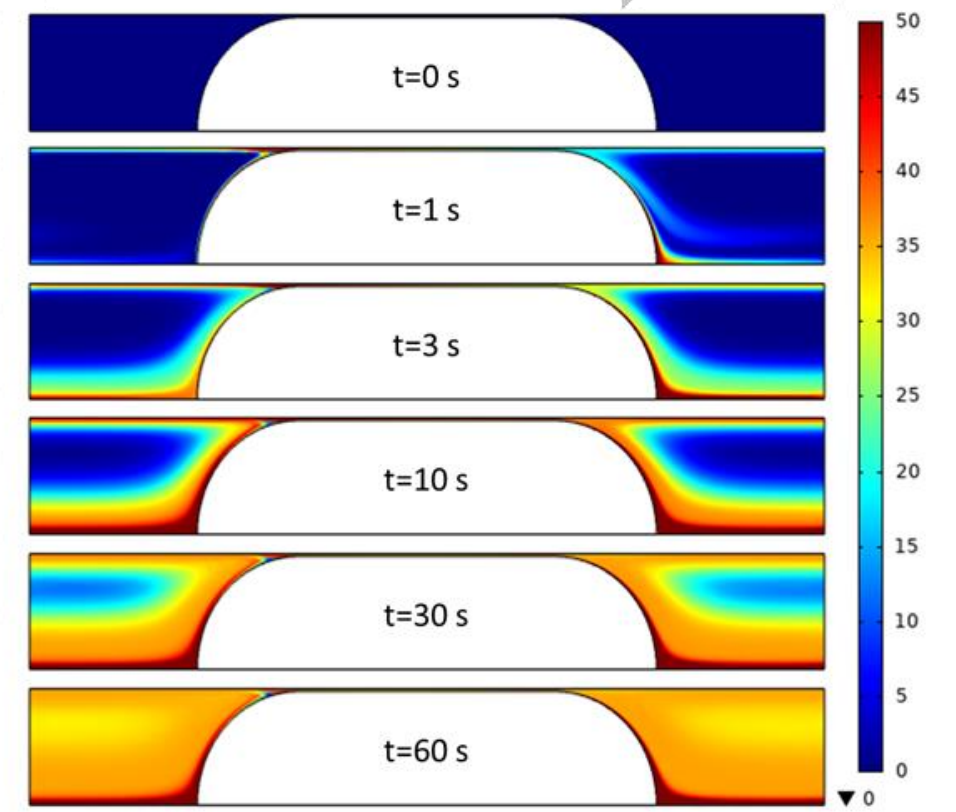

Fig. 13. Velocity field (a) and concentration profiles of $U(V I)$ in the plug (b) and slug (c) from 0 to $60 \mathrm{~s}$ for the base case $\left(d=2 \mathrm{~mm}, u_{\text {mix }}=1.06 \mathrm{~cm} \mathrm{~s}^{-1}\right.$, TBP $\left.30 \%, Q_{d} / Q_{T}=0.5\right)$.

The concentration in the aqueous phase, integrated for the whole plug, is plotted against time in Fig. 14 for the TBP $30 \%$ and the TBP 100\% cases. The trends followed by both curves are the same as those found experimentally (Fig. 11). It should be noted that the residence times are not exactly the same because the experimental one is based on the mixture velocity, while the numerical one is based on the plug velocity. The difference, however, is very small as was discussed above, and the residence times have not been adjusted. The experimental points show lower concentration in the aqueous phase and therefore, higher mass transfer. This is attributed to the high mass transfer that takes place at the inlet, where the two phases join initially; as mentioned above, this is not taken into account in the present model. 


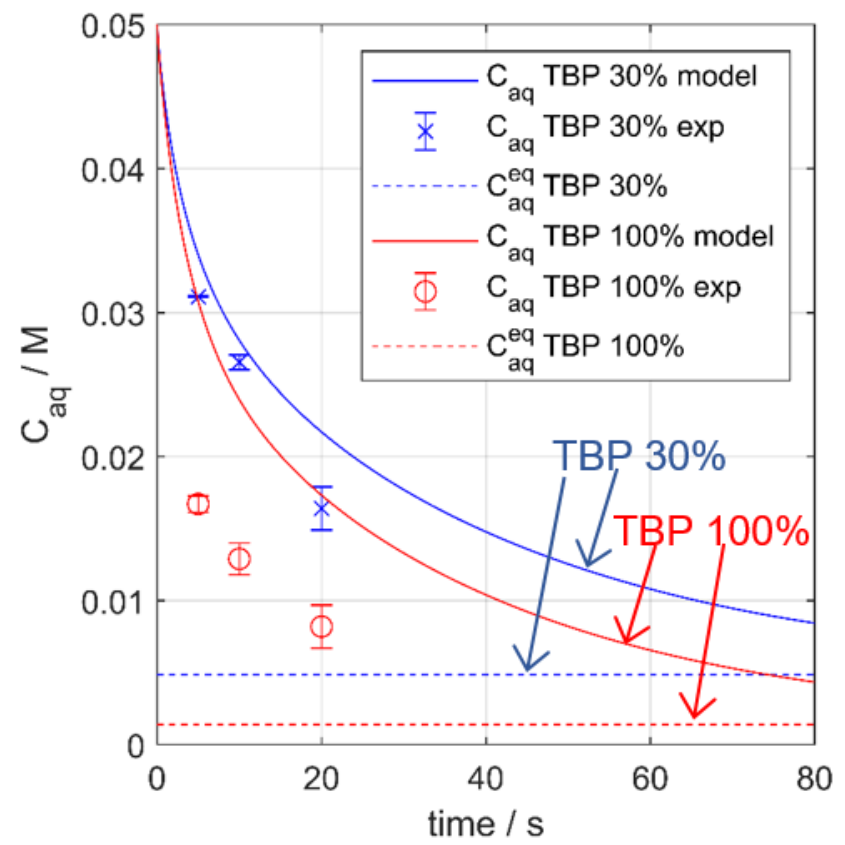

Fig. 14. Simulated and experimental average $U(V I)$ concentration in the aqueous phase against time for the base case (TBP 30\%) and the high TBP concentration case (TBP $100 \%$ ). The dashed lines represent the equilibrium concentration values $\left(\mathrm{d}=2 \mathrm{~mm}, \mathrm{u}_{\mathrm{mix}}=1.06\right.$ $\left.\mathrm{cm} \mathrm{s}^{-1}, Q_{d} / Q_{T}=0.5\right)$.

The mass transfer coefficient $\left(\mathrm{K}_{\mathrm{aq}}\right)$ can be calculated from the simulations at every consecutive time step using Eq. 20. The results are shown in Fig. 15 for the base and the $100 \%$ TBP cases. As can be seen, $K_{a q}$ decreases significantly in the beginning when there is a large concentration difference between the phases, while later ( $t>10 \mathrm{~s})$, when the uranium has been depleted from the regions close to the interphase, the change is very small. The value of $\mathrm{K}_{\mathrm{aq}}$, when it reaches a plateau, can be interpreted as a low-bound value of the mass transfer coefficient of segmented flow for those specific conditions. The experimental values of $K_{a q}$ for the same conditions between 5 and $20 \mathrm{~s}$ (Eq. 21) are shown in Fig. 15. The $K_{a q}$ experimental values are not very different and within the experimental uncertainties (reported in Table 4). Furthermore, Fig. 15 shows that, while changing the TBP concentration changes the driving force (by changing $\mathrm{C}_{\mathrm{aq}}{ }^{\mathrm{eq}}$ ), it does not affect the mass transfer coefficient significantly. 


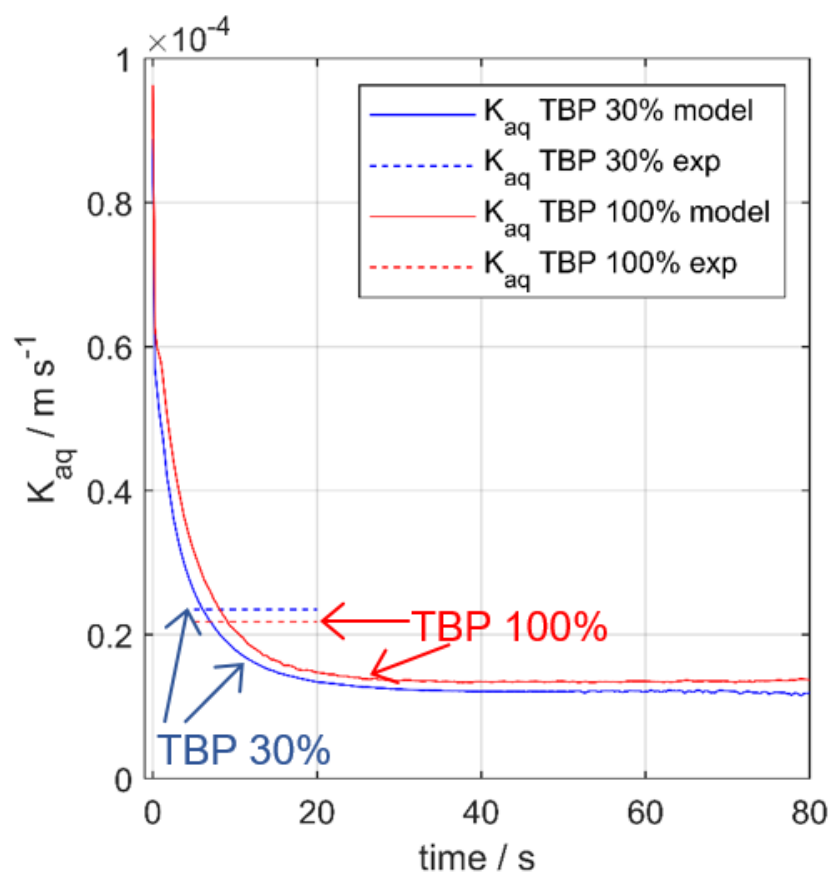

Fig. 15. Mass transfer coefficient evolution with time for the base case (TBP 30\%) and the high TBP concentration case (TBP 100\%). The dashed lines represent the experimental $\mathrm{K}_{\mathrm{aq}}$ values at the same conditions (Table 4). $\left(d=2 \mathrm{~mm}, u_{\text {mix }}=1.06 \mathrm{~cm} \mathrm{~s}^{-1}, Q_{d} / Q_{T}=0.5\right)$.

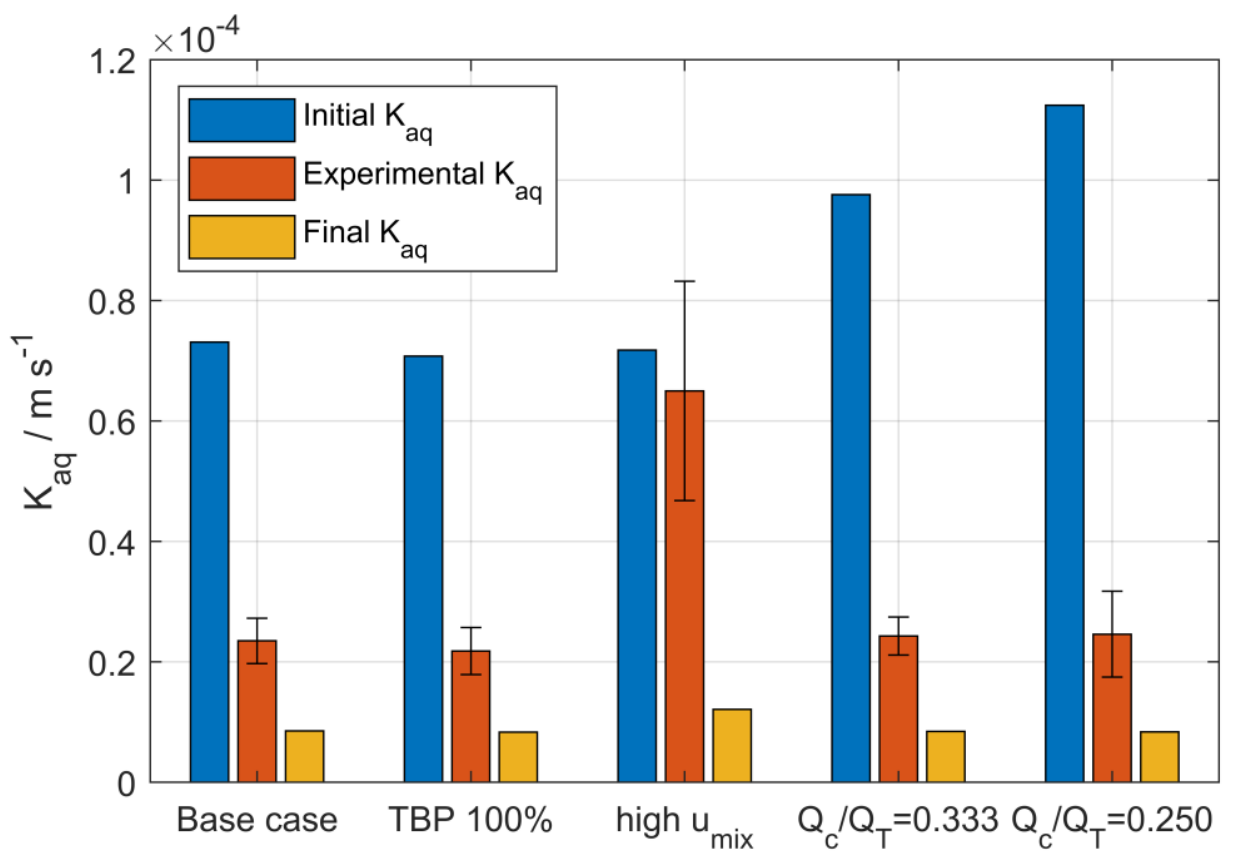

Fig. 16. Initial, experimental, and final segmented flow mass transfer coefficients $\left(K_{a q}\right)$. Initial $\mathrm{K}_{\mathrm{aq}}$ is the mass transfer coefficient for the first time step of the simulation. Final $\mathrm{K}_{\mathrm{aq}}$ is the value at which the segmented flow mass transfer coefficient converges.

Fig. 16 presents three $\mathrm{K}_{\mathrm{aq}}$ values for each case studied in Table 4. The initial $\mathrm{K}_{\mathrm{aq}}$ is the mass transfer coefficient at the first time step of the simulation $(\Delta \mathrm{T}=0.25 \mathrm{~s})$ and is the largest 
$\mathrm{K}_{\mathrm{aq}}$ value calculated, because at the initial step the concentration difference between the phases is large and the diffusion path of the solute to the interphase is small. The final low $\mathrm{K}_{\mathrm{aq}}$ is the value at which the mass transfer coefficient reaches a plateau. The experimental $\mathrm{K}_{\mathrm{aq}}$ is the value found from the measurements calculated from Eq. 21 between 5 and $20 \mathrm{~s}$. In all cases, the mean experimental value is between the initial and the final simulation values. The final $\mathrm{K}_{\mathrm{aq}}$ values are similar in all cases except for the high $\mathrm{u}_{\mathrm{mix}}$ case, which is $42 \%$ larger than the base case, because of the shorter unit length and the faster recirculation inside the plugs in this case [7].

There is limited literature available to compare the $\mathrm{K}_{\mathrm{aq}}$ values presented here for the following reasons. First, $\mathrm{K}_{\mathrm{aq}}$ depends on the system (diffusivities, viscosities) and thus, it is not strictly comparable across systems. However, as long as the viscosities, densities, and their ratios are similar, the differences could potentially be accounted for. Second, $\mathrm{K}_{\mathrm{aq}}$ is preferred over $\mathrm{K}_{\mathrm{aq}} \mathrm{a}$ for generality (the specific interfacial area depends on the system and in continuous flow contactors also on the inlet geometry) but few studies determine $\mathrm{K}_{\mathrm{aq}}$ because it would require measurements of the interfacial area. And third, many studies of flow contactors report the overall mass transfer coefficient, which includes the mass transfer that takes place in the inlet and in the outlet. This overestimates the mass transfer rates of segmented flow. Kashid et al. found mass transfer coefficients $\left(\mathrm{K}_{\mathrm{L}}\right)$ of a water/iodine/kerosene extraction between $0.5 \times 10^{-4}$ and $2 \times 10^{-4} \mathrm{~m} \mathrm{~s}^{-1}$ [21] for channels with diameters from 0.5 to $1 \mathrm{~mm}$, where the largest specific interfacial areas were 1970 and $780 \mathrm{~m}^{-1}$, respectively [33]. Li et al. found overall mass transfer coefficients ranging from $2 \times 10^{-3}$ to $7 \times 10^{-3} \mathrm{~m} \mathrm{~s}^{-1}$ using a sulphuric acid/cyclohexanone oxime/n-hexane system in a channel with a diameter of $1 \mathrm{~mm}$ [22]. Sattari-Najafabidi et al. used an acid-base reaction to study the mass transfer coefficient in microchannels with an internal diameter of $0.6 \mathrm{~mm}$ and reported mass transfer coefficients between $0.4 \times 10^{-5}$ and $1.5 \times 10^{-5} \mathrm{~m} \mathrm{~s}^{-1}$ for specific interfacial areas up to $5500 \mathrm{~m}^{-1}$ [23]. The mass transfer coefficients found by Kashid et al. [21] and Sattari-Najafabidi et al. [23] are similar to the $\mathrm{K}_{\mathrm{L}}$ values presented in Table 4 but the values found by Li et al. [22] are significantly larger. 
For packed liquid-liquid extraction columns (73 mm ID with 5/8" stainless steel Pall rings packing), Verma \& Sharma report $\mathrm{K}_{\mathrm{aq}}$ values between $3.76 \times 10^{-5}$ and $4.55 \times 10^{-5} \mathrm{~m} \mathrm{~s}^{-1}$ and specific interfacial areas $74-133 \mathrm{~m}^{-1}$. [45]. Rezvan et al. studied pulsed columns (disc and doughnut columns, with $76 \mathrm{~mm}$ ID) for a system of water/gadolinium and samarium nitrate / D2EHPA in kerosene and found $K_{a q}$ values of $5 \times 10^{-6}$ to $20 \times 10^{-6} \mathrm{~m} \mathrm{~s}^{-1}$, for specific interfacial areas from 150 to $250 \mathrm{~m}^{-1}$ [46]. Doraiswamy \& Sharma reported continuous phase mass transfer coefficients, specific interfacial areas, and dispersed phase holdups for several conventional liquid-liquid contactors, including spray and packed columns and mechanically agitated contactors [47]. They reported that the mass transfer coefficients range from $10^{-5}$ to $10^{-4} \mathrm{~m} \mathrm{~s}^{-1}$ for all types of contactors and the interfacial areas have values up to $1000 \mathrm{~m}^{-1}$. The dispersed phase holdup depends on the contactor, and in columns it has a maximum value of 0.1 , while for mechanically agitated contactors it can reach up to 0.4 .

The comparison between the $\mathrm{K}_{\mathrm{aq}}$ and a values for intensified and conventional contactors shows that intensified small channel contactors have values in similar ranges, although the a values tend to be higher in the small channel ones. To be commercially competitive the small channel contactors must, therefore, have additional advantages over conventional ones beyond the improvements in mass transfer coefficients. For the application considered here the small-channel contactors offer the following additional advantages: 1) they can handle a wide range of densities or viscosities of the two liquid phases and enable the use of the extractant without dilution thus reducing inventories, footprint, and overall volumes; 2) the flow patterns are regular, making the process easy to model, design and control, and reducing the need for over-design; and 3) the residence times are very short, thus reducing the contactor volume needed for a particular extraction, and the radiolytic damage of the solvent.

\section{Conclusions}


The hydrodynamics and mass transfer characteristics of the uranyl extraction from an aqueous solution into an organic phase were studied in small channel contactors operating in segmented flow. The design and operational variables investigated include channel internal diameters up to $4 \mathrm{~mm}$, the use of two different extractant concentrations in the organic phase, and a wide range of $u_{\text {mix }}$ and $Q_{C} / Q_{T}$ values; this expands the range of variables previously explored for uranium extraction in segmented flow contactors.

It was found that the plug, slug and unit (one plug and one slug) lengths depended mainly on the continuous phase volume fraction and the capillary number based on the continuous phase, in agreement with previous works (Table 3). Assuming that the plug is composed of two hemispherical caps and a cylindrical body, the holdup and interfacial area can be expressed as functions of plug and unit lengths, and film thickness. Correlations are proposed to estimate the holdup and dimensionless specific interfacial area, which were shown to depend only on $Q_{d} / Q_{T}, \mu_{d} / \mu_{c}$, and $C_{a}$. (Eqs. 10 and 11). The pressure gradient for segmented flow was studied experimentally and a new model, based on the flow pattern periodicity, was proposed. The proposed dimensionless model fits the experimental results well over a wide range of conditions; other available models were found to have large confidence intervals of the regression variables for the cases studied here.

The extraction efficiency and mass transfer coefficients were also obtained experimentally and compared against the predictions of a simplified numerical model. The mass transfer coefficients were mainly affected by the mixture velocity. Changes in flow rate ratio and extractant concentration affected the amount of $U$ extracted by changing the driving force or the interfacial area available but not $\mathrm{K}_{\mathrm{aq}}$.

Segmented flow contactors have large mass transfer coefficients and interfacial areas but their principal advantages over conventional contactors are the simplified modelling of the symmetric and periodic flow pattern and the ability to operate with a variety of liquid phases without viscosity or density limitations. Scaling-up the throughput of small channel contactors 
remains the main challenge towards the adoption of this technology at commercial scales. The results here demonstrate that segmented flows in relatively large channels (up to $4 \mathrm{~mm}$ diameter) have good mass transfer performance and can process high flow rates ( up to 11 litres per day or $8 \mathrm{ml} \mathrm{min}^{-1}$ or $10^{-7} \mathrm{~m}^{3} \mathrm{~s}^{-1}$ ). To increase the throughput further, scale-out approaches need to be considered, where many channels are used in parallel. The pressure gradient model proposed here (Eqs. 14-16) can be used in the design of flow distributors for scale-out (see [39]).

\section{Acknowledgements}

The project was supported by EPSRC grants (EP/P034101/1, EP/K503745, and EP/R019223). Eduardo Garciadiego-Ortega also acknowledges the support from CONACYT Mexico and UCL for his studentship.

\begin{tabular}{|c|c|}
\hline Nomenclature & \\
\hline $\mathrm{a}$ & Specific interfacial area, $\mathrm{m}^{-1}$ \\
\hline $\mathrm{A}$ & Interfacial area, $\mathrm{m}^{2}$ \\
\hline $\mathrm{A}^{\prime}$ & Cross sectional area, $\mathrm{m}^{2}$ \\
\hline $\mathrm{C}$ & Concentration, $\mathrm{mol} \mathrm{m}^{-3}$ \\
\hline $\mathrm{Ca}$ & capillary number \\
\hline $\mathrm{d}$ & Diameter, $\mathrm{m}$ \\
\hline $\mathrm{D}$ & Distribution coefficient \\
\hline $\mathrm{f}$ & Friction factor \\
\hline $\mathrm{J}$ & Jovanovic curvature parameter \\
\hline $\mathrm{K}$ & Mass transfer coefficient, $\mathrm{m} \mathrm{s}^{-1}$ \\
\hline $\mathrm{L}$ & Length, $\mathrm{m}$ \\
\hline $\mathrm{n}$ & Moles, mol \\
\hline $\mathrm{P}$ & Pressure, $\mathrm{Pa}$ \\
\hline $\mathrm{Q}$ & Volumetric flow rate, $\mathrm{m}^{3} \mathrm{~s}^{-1}$ \\
\hline $\mathrm{R}^{2}$ & Pearson correlation coefficient \\
\hline $\mathrm{Re}$ & Reynolds number \\
\hline $\mathrm{u}$ & Velocity, $\mathrm{m} \mathrm{s}^{-1}$ \\
\hline $\mathrm{V}$ & Volume, $\mathrm{m}^{3}$ \\
\hline $\mathrm{We}$ & Weber number \\
\hline Greek letters & \\
\hline $\mathrm{V}$ & Interfacial tension, $\mathrm{N} \mathrm{m}^{-1}$ \\
\hline$\delta$ & Film thickness, $\mathrm{m}^{-1}$ \\
\hline$\varepsilon$ & Volume fraction (holdup) \\
\hline$\mu$ & Viscosity, $\mathrm{Pa} \mathrm{s}$ \\
\hline
\end{tabular}




\begin{tabular}{|c|c|}
\hline$\pi$ & $\begin{array}{c}\text { Diameter-perimeter ratio of a } \\
\text { circumference }\end{array}$ \\
\hline$\rho$ & Density, $\mathrm{kg} \mathrm{m}^{-3}$ \\
\hline $\mathrm{T}$ & Residence time, $\mathrm{s}$ \\
\hline Subscripts & Aqueous phase \\
\hline $\mathrm{aq}$ & Continuous phase \\
\hline $\mathrm{c}$ & Dispersed phase \\
\hline $\mathrm{d}$ & Equilibrium \\
\hline $\mathrm{eq}$ & Hydraulic \\
\hline $\mathrm{h}$ & Inlet \\
\hline in & Liquid side \\
\hline $\mathrm{L}$ & Maximum \\
\hline max & Mixture \\
\hline mix & Outlet \\
\hline out & Plug \\
\hline $\mathrm{p}$ & Slug \\
\hline $\mathrm{s}$ & Total \\
\hline $\mathrm{T}$ & Unit \\
\hline $\mathrm{u}$ & Uranium \\
\hline$U$ & \\
\hline
\end{tabular}

\section{Appendix}

\subsection{Pressure gradient model}

As described in Section 3.2, the average pressure gradient in a tube of length $L$ with fully developed segmented flow with unit length $L_{u}$, can be modelled according to Eq. 12; assuming the pressure gradient is a periodic function, as shown by Li \& Angeli [8].

The integrand in Eq. 12 can be simplified by assuming it is composed of independent and constant contributions from the plug and slug fractions of the plug-slug unit. Eq. A1 defines the domain for each contribution; the continuous contribution runs for the length of the slug while the dispersed contribution does so for the length of the plug. The substitution of Eq. A1 in the integrand of Eq. 12 results in Eq. A2.

$$
\begin{gathered}
\left(\frac{\Delta p}{\mathrm{~L}}\right)=\left\{\begin{array}{c}
\left(\frac{\Delta \mathrm{p}}{\mathrm{L}}\right)_{\mathrm{c}} 0 \leq \mathrm{x} \leq \mathrm{L}_{\mathrm{s}} \\
\left(\frac{\Delta \mathrm{p}}{\mathrm{L}}\right)_{\mathrm{d}} \mathrm{L}_{\mathrm{s}}<\mathrm{x} \leq \mathrm{L}_{\mathrm{u}}
\end{array}\right. \\
\int_{0}^{\mathrm{L}_{\mathrm{u}}}\left(\frac{\Delta \mathrm{p}}{\mathrm{L}}\right) \mathrm{dx}=\left(\frac{\Delta \mathrm{p}}{\mathrm{L}}\right)_{\mathrm{c}} \int_{0}^{\mathrm{L}_{\mathrm{s}}} \mathrm{dx}+\left(\frac{\Delta \mathrm{p}}{\mathrm{L}}\right)_{\mathrm{d}} \int_{\mathrm{L}_{\mathrm{s}}}^{\mathrm{L}_{\mathrm{u}}} \mathrm{dx}=\left(\frac{\Delta \mathrm{p}}{\mathrm{L}}\right)_{\mathrm{c}} \mathrm{L}_{\mathrm{s}}+\left(\frac{\Delta \mathrm{p}}{\mathrm{L}}\right)_{\mathrm{d}} \mathrm{L}_{\mathrm{p}}
\end{gathered}
$$


Substituting Eq. A2 in Eq. 12 yields Eq. A3. As described in Section 3.2, the continuous contribution to the pressure gradient is modelled as being equal to the Hagen-Poiseuille flow pressure gradient (Eq. A4).

$$
\begin{gathered}
\left(\frac{\Delta \mathrm{p}}{\mathrm{L}}\right)_{\text {overall }}=\left(\frac{\Delta \mathrm{p}}{\mathrm{L}}\right)_{\mathrm{c}} \frac{\mathrm{L}_{\mathrm{s}}}{\mathrm{L}_{\mathrm{u}}}+\left(\frac{\Delta \mathrm{p}}{\mathrm{L}}\right)_{\mathrm{d}} \frac{\mathrm{L}_{\mathrm{p}}}{\mathrm{L}_{\mathrm{u}}}=\left(\frac{\Delta \mathrm{p}}{\mathrm{L}}\right)_{\mathrm{c}}\left(1-\frac{\mathrm{L}_{\mathrm{p}}}{\mathrm{L}_{\mathrm{u}}}\right)+\left(\frac{\Delta \mathrm{p}}{\mathrm{L}}\right)_{\mathrm{d}} \frac{\mathrm{L}_{\mathrm{p}}}{\mathrm{L}_{\mathrm{u}}} \\
\left(\frac{\Delta \mathrm{p}}{\mathrm{L}}\right)_{\mathrm{c}}=\frac{32 \mu_{c} \mathrm{u}_{\text {mix }}}{\mathrm{d}^{2}}
\end{gathered}
$$

Finally, substituting Eq. A4 in Eq. A3 yields Eq. 13. Using the definitions for friction factors and Reynolds numbers in Section 3.2, Eq. 14 follows directly.

\section{References}

[1] M. Benedict, T.H. Pigford, H.W. Levi, Nuclear Chemical Engineering, McGraw-Hill, 1981.

[2] K.L. Nash, G.J. Lumetta, eds., Advanced separation techniques for nuclear fuel reprocessing and radioactive waste management, Woodhead Publishing, 2011.

[3] T.C. Lo, M.H.I. Baird, C. Hanson, Handbook of solvent extraction, 1983.

[4] A. Górak, A. Stankiewicz, Intensified Reaction and Separation Systems, Annu. Rev. Chem. Biomol. Eng. 2 (2011) 431-451. https://doi.org/10.1146/annurev-chembioeng061010-114159.

[5] K.F. Jensen, Flow chemistry-Microreaction technology comes of age, AIChE J. 63 (2017) 858-869. https://doi.org/10.1002/aic.15642.

[6] K. Wang, G. Luo, Microflow extraction: A review of recent development, Chem. Eng. Sci. 169 (2017) 18-33. https://doi.org/10.1016/j.ces.2016.10.025.

[7] V. Dore, D. Tsaoulidis, P. Angeli, Mixing patterns in water plugs during water/ionic liquid segmented flow in microchannels, Chem. Eng. Sci. 80 (2012) 334-341. https://doi.org/10.1016/j.ces.2012.06.030. 
[8] Q. Li, P. Angeli, Experimental and numerical hydrodynamic studies of ionic liquidaqueous plug flow in small channels, Chem. Eng. J. 328 (2017) 717-736. https://doi.org/10.1016/j.cej.2017.07.037.

[9] P. Garstecki, M.J. Fuerstman, H.A. Stone, G.M. Whitesides, Formation of droplets and bubbles in a microfluidic T-junction—scaling and mechanism of break-up, Lab Chip. 6 (2006) 437. https://doi.org/10.1039/b510841a.

[10] T. Fu, Y. Wu, Y. Ma, H.Z. Li, Droplet formation and breakup dynamics in microfluidic flow-focusing devices: From dripping to jetting, Chem. Eng. Sci. 84 (2012) 207-217. https://doi.org/10.1016/j.ces.2012.08.039.

[11] T.A. Prileszky, B.A. Ogunnaike, E.M. Furst, Statistics of droplet sizes generated by a microfluidic device, AIChE J. 62 (2016) 2923-2928. https://doi.org/10.1002/aic.15246.

[12] D. Tsaoulidis, P. Angeli, Effect of channel size on liquid-liquid plug flow in small channels, AIChE J. 62 (2016) 315-324. https://doi.org/10.1002/aic.15026.

[13] Q. Li, P. Angeli, Intensified Eu(III) extraction using ionic liquids in small channels, Chem. Eng. Sci. 143 (2016) 276-286. https://doi.org/10.1016/j.ces.2016.01.004.

[14] A. Matsuoka, K. Noishiki, K. Mae, Experimental study of the contribution of liquid film for liquid-liquid Taylor flow mass transfer in microchannel, Chem. Eng. Sci. 155 (2016) 306-313. https://doi.org/10.1016/j.ces.2016.08.021.

[15] R. Abiev, S. Svetlov, S. Haase, Hydrodynamics and Mass Transfer of Gas-Liquid and Liquid-Liquid Taylor Flow in Microchannels, Chem. Eng. Technol. 40 (2017) 19851998. https://doi.org/10.1002/ceat.201700041.

[16] S. Haase, Characterisation of gas-liquid two-phase flow in minichannels with coflowing fluid injection inside the channel, part II: gas bubble and liquid slug lengths, film thickness, and void fraction within Taylor flow, Int. J. Multiph. Flow. 88 (2017) 
251-269. https://doi.org/10.1016/j.jmultiphaseflow.2016.09.002.

[17] M.T. Kreutzer, F. Kapteijn, J.A. Moulijn, C.R. Kleijn, J.J. Heiszwolf, Inertial and interfacial effects on pressure drop of Taylor flow in capillaries, AIChE J. 51 (2005) 2428-2440. https://doi.org/10.1002/aic.10495.

[18] J. Jovanović, W. Zhou, E. V. Rebrov, T.A. Nijhuis, V. Hessel, J.C. Schouten, Liquidliquid slug flow: Hydrodynamics and pressure drop, Chem. Eng. Sci. 66 (2011) 42-54. https://doi.org/10.1016/j.ces.2010.09.040.

[19] M. Mac Giolla Eain, V. Egan, J. Howard, P. Walsh, E. Walsh, J. Punch, Review and extension of pressure drop models applied to Taylor flow regimes, Int. J. Multiph. Flow. 68 (2015) 1-9. https://doi.org/10.1016/j.ijmultiphaseflow.2014.09.006.

[20] D. Tsaoulidis, V. Dore, P. Angeli, N. V. Plechkova, K.R. Seddon, Flow patterns and pressure drop of ionic liquid-water two-phase flows in microchannels, Int. J. Multiph. Flow. 54 (2013) 1-10. https://doi.org/10.1016/j.jjmultiphaseflow.2013.02.002.

[21] M.N. Kashid, Y.M. Harshe, D.W. Agar, Liquid-liquid slug flow in a capillary: An alternative to suspended drop or film contactors, Ind. Eng. Chem. Res. 46 (2007) 8420-8430. https://doi.org/10.1021/ie070077x.

[22] L. Li, J. Zhang, C. Du, G. Luo, Determination of the Liquid/Liquid Mass Transfer Coefficient for Each Phase in Microchannels, Ind. Eng. Chem. Res. 57 (2018) 90289036. https://doi.org/10.1021/acs.iecr.8b01976.

[23] M. Sattari-najafabadi, M.N. Nasr Esfahany, M.N. Esfahany, M.N. Nasr Esfahany, Intensification of liquid-liquid mass transfer in a circular microchannel in the presence of sodium dodecyl sulfate, Chem. Eng. Process. Process Intensif. 117 (2017) 9-17. https://doi.org/10.1016/j.cep.2017.03.011.

[24] D. Tsaoulidis, P. Angeli, Effect of channel size on mass transfer during liquid - liquid 
plug flow in small scale extractors, Chem. Eng. J. 262 (2015) 785-793.

https://doi.org/10.1016/j.cej.2014.10.012.

[25] M. Sattari-Najafabadi, M. Nasr Esfahany, Z. Wu, B. Sunden, Mass transfer between phases in microchannels: A review, Chem. Eng. Process. - Process Intensif. 127 (2018) 213-237. https://doi.org/10.1016/j.cep.2018.03.012.

[26] C. Mariet, A. Vansteene, M. Losno, J. Pellé, J.P. Jasmin, A. Bruchet, G. Hellé, Microfluidics devices applied to radionuclides separation in acidic media for the nuclear fuel cycle, Micro Nano Eng. 3 (2019) 7-14. https://doi.org/10.1016/j.mne.2019.02.006.

[27] N. Sen, M. Darekar, K.K. Singh, S. Mukhopadhyay, K.T. Shenoy, S.K. Ghosh, Solvent Extraction and Stripping Studies in Microchannels with TBP Nitric Acid System, Solvent Extr. Ion Exch. 32 (2014) 281-300. https://doi.org/10.1080/07366299.2013.850290.

[28] M. Darekar, K.K. Singh, S. Mukhopadhyay, K.T. Shenoy, S.K. Ghosh, Solvent extraction in microbore tubes with UNPS-TBP in dodecane system, Sep. Purif. Technol. 128 (2014) 96-105. https://doi.org/http://dx.doi.org/10.1016/j.seppur.2014.03.002.

[29] M. Darekar, K.K. Singh, S. Mukhopadhyay, K.T. Shenoy, Single-stage micro-scale extraction: Studies with single microbore tubes and scale-up, Sep. Purif. Technol. 158 (2016) 160-170. https://doi.org/10.1016/j.seppur.2015.11.041.

[30] M. Darekar, K.K. Singh, P. Sapkale, A.K. Goswami, S. Mukhopadhyay, K.T. Shenoy, On microfluidic solvent extraction of uranium, Chem. Eng. Process. - Process Intensif. 132 (2018) 65-74. https://doi.org/10.1016/j.cep.2018.08.007.

[31] T. Wang, T. Xie, C. Xu, Microextractors applied in nuclear-spent fuel reprocessing: Micro/mini plants and radiochemical analysis, Crit. Rev. Environ. Sci. Technol. 0 
(2018) 1-31. https://doi.org/10.1080/10643389.2018.1530051.

[32] D. Bascone, P. Angeli, E.S. Fraga, Mathematical modelling of intensified extraction for spent nuclear fuel reprocessing, Nucl. Eng. Des. 332 (2018) 162-172. https://doi.org/10.1016/j.nucengdes.2018.03.030.

[33] D. Bascone, P. Angeli, E.S. Fraga, A modelling approach for the comparison between intensified extraction in small channels and conventional solvent extraction technologies, Chem. Eng. Sci. 203 (2019) 201-211. https://doi.org/10.1016/j.ces.2019.03.074.

[34] M. Mac Giolla Eain, V. Egan, J. Punch, Film thickness measurements in liquid-liquid slug flow regimes, Int. J. Heat Fluid Flow. 44 (2013) 515-523. https://doi.org/10.1016/j.ijheatfluidflow.2013.08.009.

[35] S. Kerisit, C. Liu, Molecular simulation of the diffusion of uranyl carbonate species in aqueous solution, Geochim. Cosmochim. Acta. 74 (2010) 4937-4952. https://doi.org/10.1016/j.gca.2010.06.007.

[36] V. Friehmelt, A. He, Z. Yang, G. Marx, The diffusion coefficients and viscosities of the UO2(NO3)2·2TBP complex in organic solvents, Inorganica Chim. Acta. 111 (1986) 89-93. https://doi.org/10.1016/S0020-1693(00)82223-9.

[37] G. James, D. Witten, T. Hastie, Introduction to Statistical Learning : with Applications in R, Springer, New York, 2013.

[38] Z. Cao, Z. Wu, B. Sundén, Dimensionless analysis on liquid-liquid flow patterns and scaling law on slug hydrodynamics in cross-junction microchannels, Chem. Eng. J. 344 (2018) 604-615. https://doi.org/10.1016/j.cej.2018.03.119.

[39] E. Garciadiego Ortega, D. Tsaoulidis, P. Angeli, Predictive model for the scale-out of small channel two-phase flow contactors, Chem. Eng. J. 351 (2018) 589-602. 
https://doi.org/10.1016/j.cej.2018.06.020.

[40] F.P. Bretherton, The motion of long bubbles in tubes, J. Fluid Mech. 10 (1961) 166. https://doi.org/10.1017/S0022112061000160.

[41] S.F. Ellermeyer, D.G. Robinson, Integrals of Periodic Functions, Math. Mag. 74 (2001) 393. https://doi.org/10.2307/2691036.

[42] K. Miyabayashi, O. Tonomura, S. Hasebe, Estimation of gas and liquid slug lengths for T-shaped microreactors, Chem. Eng. J. 262 (2015) 1137-1143. https://doi.org/10.1016/j.cej.2014.10.075.

[43] R.B. Bird, W.E. Stewart, E.N. Lightfoot, Transport Phenomena, 2nd ed., John Wiley \& Sons, New York, 2002.

[44] J.R. Welty, C.E. Wicks, R.E. Wilson, Fundamentals of Momentum, Heat, and Mass Transfer, 2nd ed., John Wiley \& Sons, New York, 1976.

[45] R.P. Verma, M.M. Sharma, Mass transfer in packed liquid-liquid extraction columns, Chem. Eng. Sci. 30 (1975) 279-292. https://doi.org/10.1016/0009-2509(75)80078-9.

[46] R. Torkaman, M. Torab-Mostaedi, J. Safdari, M.A. Moosavian, M. Asadollahzadeh, Mass transfer coefficients in pulsed column for separation of samarium and gadolinium, Iran. J. Chem. Chem. Eng. 36 (2017) 145-158.

[47] L.K. Doraiswamy, M.M. Sharma, Heterogeneous reactions : analysis, examples, and reactor design, John Wiley \& Sons, New York, 1984. 